\title{
The Influence of Diol Chain Extender on Morphology and Properties of Thermally-Triggered UV-Stable Self-Healing Polyurethane Coatings
}

\author{
Adam W. Grzelak, Pascal Boinard, John J. Liggat* \\ WestCHEM, Department of Pure and Applied Chemistry, University of Strathclyde, 295 Cathedral Street, Glasgow, \\ G1 IXL, UK \\ *Corresponding author: email j.j.liggat@strath.ac.uk
}

\begin{abstract}
Two sets of waterborne polyurethane dispersions were synthesised from polycarbonate polyol with molecular mass of $500 \mathrm{Da}$ and hexamethylene diisocyanate or isophorone diisocyanate. Formulations were prepared without a chain extender, with aliphatic diol with two to five carbon atoms or with diethylene glycol. Coatings were prepared on cellulose triacetate sheets, damaged by a steel-wool scratch instrument and left to heal at room temperature and at $60^{\circ} \mathrm{C}$. Self-healing efficiency was examined by comparison of haze before damage and at intervals after damage. Samples were analysed using Differential Scanning Calorimetry, Attenuated Total Reflectance Fourier Transform Infrared Spectroscopy, Scanning Electron Microscopy. The tests were repeated after 12 weeks to investigate ageing of the polymers. Samples were also tested for their stability to weathering.

Optimally designed coatings obtained up to $100 \%$ recovery within 10 minutes at $60^{\circ} \mathrm{C}$ and partial recovery at room temperature. The self-healing properties of coatings were found to be linked to macro-organisation of polymer chains caused by interactions between hard segments and soft segments of the polyurethane moiety, leading to phase-mixing, promoted by bulky, non-symmetrical isophorone diisocyanate, or phase-separation, promoted by linear, symmetrical hexamethylene diisocyanate. The length of chain extender was found to have large influence on formulations prepared with hexamethylene diisocyanate, increasing phase-separation and haze with the increase of chain length. Diethylene glycol was found to improve phase-mixing and self-healing properties of hexamethylene diisocyanate based materials. The influence of chain extenders was found to be minimal for isophorone diisocyanate based materials.
\end{abstract}

Keywords: polyurethane; self-healing; coatings; phase-mixing; morphology 


\section{Introduction}

The development of hard and efficiently self-healing (SH) transparent coatings has been a research goal of many scientists [1]. The use of such materials electronic devices with touch screens or other surfaces sensitive to damage could improve the service life of such items and improve customer satisfaction.

Polyurethanes (PU) are one of the most attractive materials with potential for use as SH coatings. These polymers show unique physical and mechanical properties and are already being widely used as protective coatings, lacquers and varnishes [2]. Due to their internal structure, two phases can be distinguished - rigid, polar hard segments (HS), formed by isocyanate and chain extenders (CE), and flexible, non-polar soft segments (SS) formed by long chain polyols [3]. As the result of their polar nature, HS tend to attract each other, aggregate and form hydrogen-bonded blocks [4]. The resulting copolymer can be considered as composed of islands of HS with higher glass transition temperatures $\left(\mathrm{T}_{\mathrm{g}}\right)$ dispersed in SS of lower $\mathrm{T}_{\mathrm{g}}$, acting as physical cross-links providing toughness and elasticity [5]. Phase-separation facilitates packing of polymer chains within each phase, leading to highly organised structures, increased crystallinity in both phases where appropriate, and consequently higher haze in coatings as light scatters from the HS domains and/or crystallites. On the other hand, favourable interactions between HS and SS will lead to phase-mixing of the polyurethane matrix (Figure 1). Phase-mixed systems tend to be more amorphous with smaller domain sizes and lower crystallinity and thus lower haze $[6,7]$.

(a)

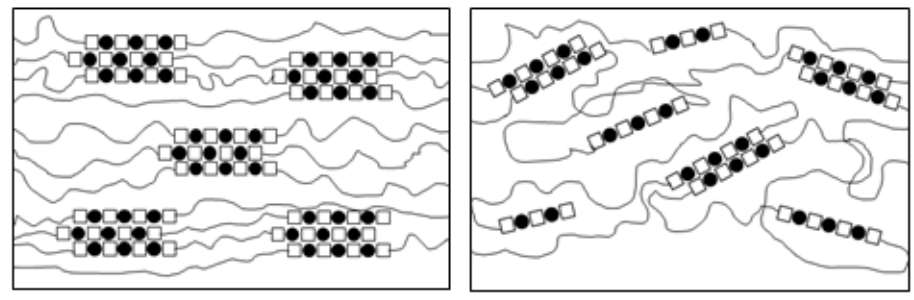

(๑ chain extender; $\square$ isocyanate; - - polyol)

Figure 1 Morphology of polyurethane matrix: (a) phase-separation and (b) phase-mixing. 
The presence of non-covalent supramolecular interactions, such as H-bonds creating the secondary structure of PU, is known to enable self-repair properties of a damaged polymer matrix [8]. Cordier et al. designed and synthesised highly crosslinked (via H-bonding) materials that repeatedly healed, bringing together broken surfaces at room temperature [9]. The healing model was further studied and explained using computer simulations [10]. Clustering of H-bonded supramolecular rubber was investigated by Herbst and co-workers [11]. They suggested that the SH of fractures was explained by a dynamic behaviour of the network and thermoreversible aggregation and de-aggregation of supramolecular clusters. Moreover, Chen et al. reported that microphase separation of supramolecular moieties, obtained via supramolecular block copolymer architectures, induced SH behaviour [12]. In the novel, thermoresponsive material presented by Burattini et al. $\pi-\pi$ stacking interactions, rather than H-bonding, led to formation of reversible network responsible for healable characteristics [13]. The thermal healability was further improved by combining $\pi$ - $\pi$ stacking interactions and interpolymer hydrogen bonding [14]. Later, Burnworth et al. presented rubbery metallosupramolecular polymers with non-covalent metal-ligand motifs converting a UV light energy into heat to quickly and efficiently dissociate and heal the defects [15]. Ghosh et al. observed lowering of $\mathrm{T}_{\mathrm{g}}$ inside the scratch of damaged polymers, explained by a damage-induced chain scission and recombination reactions [16] and supported using molecular dynamics simulations [17]. Furthermore, rheological studies of supramolecular healing supported with reversible chemical disulphide bonds were reported by Grande et al. [18].

The phase-separation of PU [19] is dependent on the extent of H-bonds between the segments, as well as synthetic pathway and reaction conditions [20]. However, the key factor that influences the morphology of PU is the choice of molecular building blocks [6]. Phase-mixing was found to increase with a decrease of molecular mass of polyols by Eceiza et al [21]. Garcia-Pacios et al. reported that lowering of the molecular mass of polyol led to an increase of coatings hardness and decrease of elastic modulus, $\mathrm{T}_{\mathrm{g}}$, gloss and yellowing index [22], while Lee et al. showed an increase of solvent swelling, emulsion viscosity and decrease of elongation at break [23]. Selim et al. and Gomez et al. reported that symmetric and linear diisocyanates, such as hexamethylene diisocyanate (HDI), promote crystallinity and phase-separation via long-range ordering of hydrogen bonds, while asymmetrical and bulky isophorone diisocyanate (IPDI) promotes phase-mixing [24,25]. In other studies it was observed that $\mathrm{CE}$ with even number of carbon atoms, with the exception of ethylene glycol, promote crystallinity and packing [26-28]. 
The relationship between morphology of PU and efficiency of SH was also studied in recent years. Ardjmand and Rad showed the influence of $\mathrm{CE}$ and isocyanate to polyol ratio on healing of automotive PU coatings [5]. The effect of molecular weight of PU and the amount of crosslinking on SH properties was explored by Kim et al. [29]. Gonzalez-Garcia et al. monitored thermal relaxation of SS during healing of damaged shape-memory PU coatings [30]. Additionally, a number of studies focused on improvement of supramolecular healing by introduction of reversible Diels-Alder crosslinks [31,32].

Despite all this previous research, there remains a gap in the understanding of the morphology and healing efficiency of protective coatings for optical applications. For such systems, there is clearly a need to also optimise clarity, bringing with it the need to further control the morphology. To the best of our knowledge, there are no studies reporting the influence of aliphatic diol CE on SH properties of polycarbonate-based transparent PU coatings. This article, therefore, reports synthesis of two sets of polyurethane dispersions (PUDs) prepared from copolycarbonate diol with HDI or IDPI. Coatings prepared without chain extender, with aliphatic diols with two to five carbon atoms or with diethylene glycol were investigated to evaluate their SH properties, pencil hardness and cross-cut adhesion. Additionally, polymer morphology analyses was performed using Differential Scanning Calorimetry (DSC), Attenuated Total Reflectance Fourier Transform Infrared Spectroscopy (ATR FT-IR) and Scanning Electron Microscope (SEM), focusing on identification of the relationship between the diisocyanate, $\mathrm{CE}$ and $\mathrm{SH}$ performance.

\section{Materials and Methods}

\section{Materials}

PH50, a copolycarbonate of pentanediol and hexanediol with MW of $500 \mathrm{Da}$ (generously donated by UBS Industries), dried overnight in a vacuum oven at $80^{\circ} \mathrm{C}$, was used as the polyol. Hexamethylene diisocyanate (HDI, $>98 \%$ ), isophorone diisocyanate (IPDI, >98\%), ethylene glycol (1,2-EG, 99\%), 1,3-propanediol (1,3-PrD, 99\%), 1,4-butanediol (1,4-BD, 99\%), 1,5-pentanediol (1,5-PeD, 99\%), diethylene glycol (DEG, 99\%), dimethylol propionic acid (DMPA, 98\%), dibutyltin dilaurate (DBTDL, 95\%), and triethylamine (TEA, 99.5\%) were purchased from Sigma Aldrich and used without further purification. Acetone (99\%), distilled before use, was purchased from Sigma Aldrich. Additionally, deionised water was used as a dispersing phase. 


\section{Synthesis of the polyurethane dispersions}

PUDs were prepared using the so-called acetone process [33]. Dry polyol (10 g, $20 \mathrm{mmol})$, DMPA $(0.67 \mathrm{~g}, 5 \mathrm{mmol})$ and DBTDL $(0.2 \mathrm{~mL}, 0.03 \mathrm{mmol})$ were placed in an oven-dried reaction vessel. 20 $\mathrm{mL}$ of anhydrous acetone and TEA $(0.67 \mathrm{~g}, 7 \mathrm{mmol})$ were subsequently added. The mixture was stirred under nitrogen at $200 \mathrm{rpm}$ for 30 minutes at $50^{\circ} \mathrm{C}$, after which the isocyanate $(40 \mathrm{mmol}$ for formulations with CE, $25 \mathrm{mmol}$ for formulations without $\mathrm{CE}$ ) was added drop-wise. Optionally, after 2-4 hours CE (15 mmol) was added. The progress of the reaction was monitored by ATR FT-IR spectroscopy until a complete disappearance of NCO peak was observed. Subsequently, the mixture was cooled down to room temperature (RT), $30-50 \mathrm{~mL}$ of water was added and the solution was stirred at $600 \mathrm{rpm}$ for 30 minutes to create polyurethane dispersion. Acetone was removed in rotary evaporator over 60 minutes at $50^{\circ} \mathrm{C}$ and 300 mbar pressure.

\section{Preparation of the polyurethane coatings}

Approximately $2 \mathrm{~mL}$ of PUDs were applied with a wire-wound Mayer bar size 020 (20 mils/50.8 microns wet coating thickness) on cellulose triacetate (TAc) sheets cut into pieces of 400x600 mm. The coated sheets were placed in the oven at $60^{\circ} \mathrm{C}$ for 1 hour to ensure complete removal of water. Subsequently small samples of size 40x60 mm were cut and used for further tests.

\section{Experimental techniques}

Solid content (\%S). 10-30 mg of the dispersion was placed in a small pre-weighted aluminium pan and left overnight in the oven at $80^{\circ} \mathrm{C}$. The solid content was calculated as an average of three measurements of a difference in weight of the PUDs before and after drying.

Hard segment content $(\% H S)$. The materials were designed to contain approximately $50 \%$ of HS. The exact hard segment content $(\% \mathrm{HS})$ was calculated as combined urethane and urea proportion of the polymer using Equation 1, where $R$ is the mole ratio of isocyanate to polyol and $M_{i s o}, M_{C E}$ and $\mathrm{M}_{\mathrm{ol}}$ are respectively number average molar masses of isocyanate, $\mathrm{CE}$ and polyol [34].

$$
\% H S=\frac{R \times M_{i s o}+(R-1)\left(M_{C E}\right)}{M_{o l}+R \times M_{i s o}+(R-1) \times M_{C E}} \times 100
$$

Pencil hardness test. The hardness of PU coatings was measured using the pencil hardness test, standard ISO 15184:2012. Coated TAc sheets were placed on a firm horizontal surface. The pencil was placed in a pencil hardness test device designed to keep the pencil at a $45^{\circ}$ angle. The tester was 
placed on the surface of the coating and pushed in two parallel 20-50 $\mathrm{mm}$ strokes. The process was started with the hardest pencil and continued down the scale of hardness until the pencil did not cause damage of the coating.

Cross-cut adhesion test. The adhesion of PU coatings was measured using the cross-cut test standard ISO 2409:2007. The cross-cut was made using an Elcometer 107 Cross Hatch Cutter. Two cuts at $90^{\circ}$ to each other were made through the coating. Detached coating was removed with a soft brush. An adhesive tape was placed over the cut and smoothed into the place using the brush. Subsequently the tape was removed by pulling it off rapidly at $60^{\circ}$ and delamination of the coating was evaluated under magnifying glass. Adhesion was assessed on a 0 to 5 scale $(0-0 \%$ flaking, 5 - more than $65 \%$ flaking).

Haze measurement. All haze measurements were performed with a BYK Gardner Haze-Guard Dual instrument. The haze was calculated as an average of three measurements.

Scanning Electron Microscopy. Coated TAc sheets were cut into 10x10 mm squares, covered with a thin layer of silver using a sputter coater and analysed using a Cambridge Scanning Electron Microscopy Stereoscan 90.

Weathering. Weathering tests were carried out using Atlas Suntest XLS+ weatherometer, equipped with a daylight filter with a cut-off at $290 \mathrm{~nm}$. The coated TAc sheets were placed in the chamber using a metal frame and exposed to an irradiation intensity of $(365 \pm 35) \mathrm{W} \mathrm{m}^{-2}$, measured between $290-800 \mathrm{~nm}$, and a temperature of $(37.5 \pm 2.5)^{\circ} \mathrm{C}$, and left for 4 weeks under constant UV exposure. ATR FT-IR spectra of the coatings were taken before and after the weathering.

Infrared spectroscopy (ATR FT-IR). The spectra were obtained with Agilent 5500 Series ATR FT-IR instrument using 128 scans at resolution $2 \mathrm{~cm}^{-1}$. The spectra are reported as a baseline-corrected and normalised average of three measurements.

Differential scanning calorimetry (DSC). DSC measurements were carried out using TA Q1000 DSC instrument. Aluminium pans with 5-15 mg of solid PU samples underwent a heat-cool-heat cycle ($90^{\circ} \mathrm{C} / 150^{\circ} \mathrm{C} /-90^{\circ} \mathrm{C} / 300^{\circ} \mathrm{C}$ ) at $20^{\circ} \mathrm{C} / \mathrm{min}$ heating/cooling rate under nitrogen atmosphere (flow rate 40 $\mathrm{mL} / \mathrm{min}$ ). The glass transition temperatures are reported as a midpoint at half-height. 
Damage of coatings. The coatings were damaged using a Lima TRS automated steel wool instrument. Introduction of damage was performed by 40 back-and-forth scratch cycles using 000 grade steel wool under $500 \mathrm{~g}$ load. The initial haze of a coating (iH) was measured before damage and the scratched haze of coatings $(\mathrm{sH})$ was measured immediately after damage. The percentage of damage was calculated for all the samples tested as a ratio of total damage caused by scratching, which is a difference between haze of damaged $(\mathrm{sH})$ and undamaged (iH) sample, to undamaged haze (iH) (Equation 2).

$$
\text { Damage }=\frac{s H-i H}{i H} \times 100 \%
$$

Recovery of coatings at room temperature. The self-healing efficiency was determined by haze measurements $(\mathrm{H})$ of samples left at room temperature for 3 hours in 10-30 minutes intervals. Percentage of recovery was calculated as a ratio of change in haze during recovery, which is a difference between haze of damaged $(\mathrm{sH})$ and recovering $(\mathrm{H})$ sample at time, to a total damage caused by scratching, which is a difference between haze of damaged $(\mathrm{sH})$ and undamaged $(\mathrm{iH})$ sample (Equation 3).

$$
\text { Recovery }=\frac{s H-H}{s H-i H} \times 100 \%
$$

Recovery of coatings at $60^{\circ} \mathrm{C}$. The self-healing efficiency was determined by haze measurements $(\mathrm{H})$ of samples left in the oven at $60^{\circ} \mathrm{C}$ for 30 minutes in 10 minutes intervals. Percentage of recovery was calculated using Equation 3.

\section{Results and discussion}

\section{Characterisation of the materials}

Two sets of coating materials were prepared - HDI-based and IPDI-based formulations. The list of formulations and percentage content solid of the dispersions are presented in Table 1. The nomenclature of the polyurethanes used in the table and henceforth consists of the abbreviation of polycarbonate polyol, PH50, followed by abbreviation of the diisocyanate, HDI or IPDI, and abbreviation of the CE used.

Table 1 Characterisation of PU dispersion and coatings data 


\begin{tabular}{lcccccc}
\hline Polyurethane & $\begin{array}{c}\text { Solid content } \\
(\mathbf{w t} \%)\end{array}$ & $\begin{array}{c}\text { Hard segments } \\
(\%)\end{array}$ & Pencil Hardness & $\begin{array}{c}\text { Cross-Cut Adhesion } \\
\text { (Haze - original } \\
(\%)\end{array}$ & $\begin{array}{c}\text { Haze - 12 weeks } \\
(\%)\end{array}$ \\
\hline PH50-HDI & $32.9 \pm 2.7$ & 39.0 & B & 0 & 1.08 & 7.77 \\
PH50-HDI-1,2-EG & $27.4 \pm 1.7$ & 45.4 & HB & 0 & 1.04 & 1.57 \\
PH50-HDI-1,3-PrD & $15.8 \pm 7.5$ & 46.1 & 2B & 5 & 34.83 & - \\
PH50-HDI-1,4-BD & $27.5 \pm 2.6$ & 46.7 & 2B & 5 & 69.00 & 71.53 \\
PH50-HDI-1,5-PeD & $11.8 \pm 2.1$ & 47.3 & 2B & 5 & 92.93 & - \\
PH50-HDI-DEG & $27.8 \pm 2.8$ & 47.3 & HB & 0 & 0.45 & 1.51 \\
\hline PH50-IPDI & $29.4 \pm 3.1$ & 44.5 & 2B & 0 & 0.21 & 1.16 \\
PH50-IPDI-1,2-EG & $23.1 \pm 1.1$ & 51.2 & B & 0 & 0.77 & 0.94 \\
PH50-IPDI-1,3-PrD & $26.8 \pm 4.2$ & 51.7 & 2B & 5 & 0.44 & - \\
PH50-IPDI-1,4-BD & $24.3 \pm 1.0$ & 52.2 & B & 5 & 0.44 & 1.34 \\
PH50-IPDI-1,5-PeD & $27.4 \pm 3.6$ & 52.7 & 2B & 5 & 0.60 & - \\
PH50-IPDI-DEG & $23.5 \pm 1.0$ & 52.7 & 2B & 5 & 0.33 & 1.05 \\
\hline
\end{tabular}

The experimental solid content of dispersions varied between $11.8 \%$ and $32.9 \%$, dependent on solubility of polymer in water and the viscosity of the dispersion. The percentage of hard segments varied from $39.0 \%$ to $52.7 \%$ and was influenced by the isocyanate and CE used. The hardness of coatings varied between $\mathrm{HB}$ and $2 \mathrm{~B}$. The cross-cut adhesion was found to be 0 for samples prepared with no $\mathrm{CE}$ or 1,2-EG and decreased for longer $\mathrm{CE}$.

Coatings prepared with IPDI exhibited very low haze values within the acceptable $0-2 \%$ haze level, indicative of phase-mixed morphology. The phase-mixing can be explained by a bulky, nonsymmetrical structure of the diisocyanate used, leading to creation of complex, multidimensional and not easily-packed polymer network. Coatings prepared with HDI showed a broad scope of haze values, increasing with the length of CE. The linear and symmetrical structure of HDI facilitates packing of the polymer chains in the HS, promoting phase-separation. As the HS consist of diisocyanate and CE, the length of CE will influence the size of hard blocks, and the size of the phase domains, increasing haze. Interestingly, the presence of heteroatom within the structure of the CE DEG significantly lowered the haze of coatings due to disturbance of the packing of HS.

The haze value of selected samples measured after 12 weeks was found to somewhat increase. The largest change is observed for samples prepared without CE, followed by samples prepared with DEG, indicative of continued rearrangement of the phase-mixed polymer matrices and increase of phase-separation.

The SEM images showed a relationship between the haze and the coating's surface morphology (Figure 2). The high-haze coatings prepared with HDI showed an uneven and grainy surface. The roughness, caused by a fast crystallisation of large HS blocks close to the surface of coatings, leads 
to formation of regions of different refractive index and increases overall haze value $[35,36]$. Such an effect was not observed in more phase-mixed and amorphous coatings prepared with IPDI (see Supplementary Material).
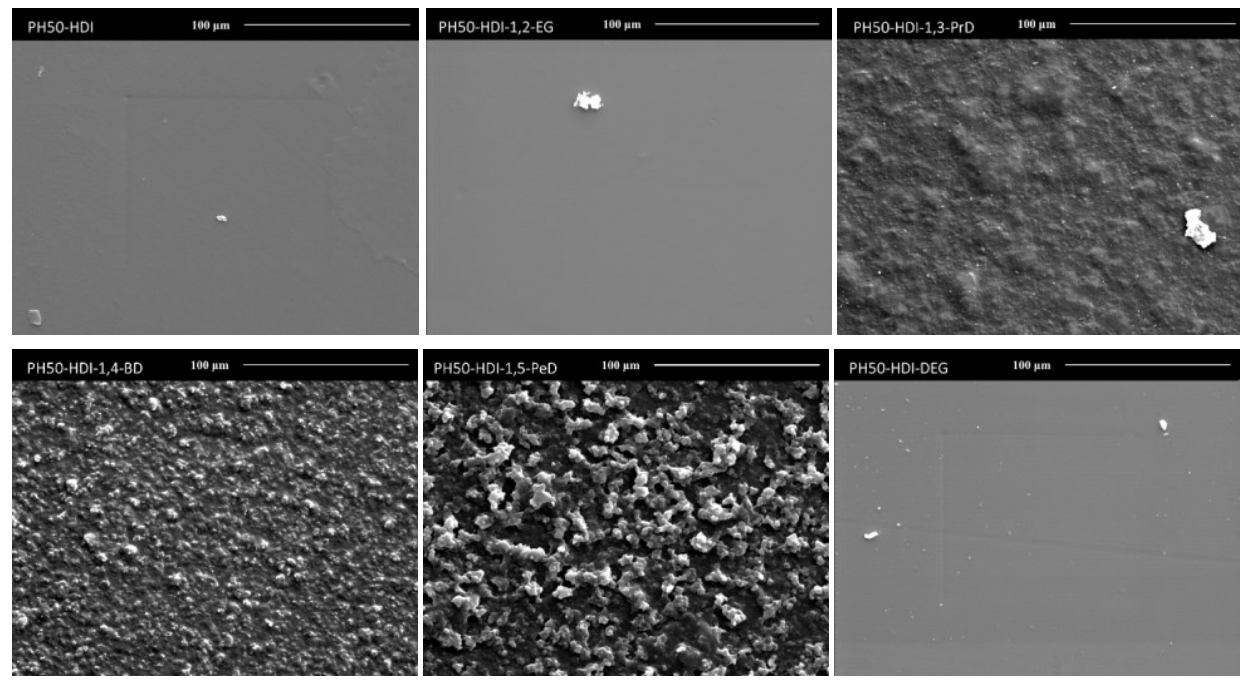

Figure 2 SEM images of coatings prepared with HDI

\section{Characterisation of polyurethane coating morphology}

DSC analysis

DSC plots of coatings prepared with HDI are presented in Figure 4. It is important to consider both first and second heating cycles. The first heat cycle shows the morphology (and hence thermal) properties of the samples "as-coated", whilst the second heat cycle provides information on the morphology subsequent to the imposition of an identical thermal history on all samples.

The $\mathrm{T}_{\mathrm{g}}$ values of all samples prepared with HDI were found to be below $0^{\circ} \mathrm{C}$, varying from $-22^{\circ} \mathrm{C}$ to $17^{\circ} \mathrm{C}$ in the first heat cycle and $-17^{\circ} \mathrm{C}$ to $-8^{\circ} \mathrm{C}$ in the second. In the second cycle, $\mathrm{T}_{\mathrm{g}}$ values were found mostly to decrease with the increase of the CE length. The $\mathrm{T}_{\mathrm{g}}$ is that of the amorphous region of the SS and lower values are associated with increased phase-separation. The samples prepared without CE or with DEG show a deviation from this trend due to increased phase-mixing of the systems after the thermal cycling. The hardness of the samples at RT (Table 1) indicates that the observed glass transitions are associated with amorphous regions of semi-crystalline SS. The lack of 
an observable separate glass transition associated with phase-separated HS suggests a high degree of crystallinity of the polar phase.

Multiple melting peaks can be observed in the first heat cycle of all samples but PH50-HDI, associated with crystalline regions of semi-crystalline soft segments. The smallest enthalpy of melting was observed for formulations prepared without $\mathrm{CE}$, indicative of a more phase-mixed (and hence less crystalline) morphology. Interestingly, in the second heat cycle, only the sample prepared with 1,4-BD shows cold crystallisation and melting. The behaviour can be explained as the presence of 1,4-BD is particularly known to promote phase-separation [27].

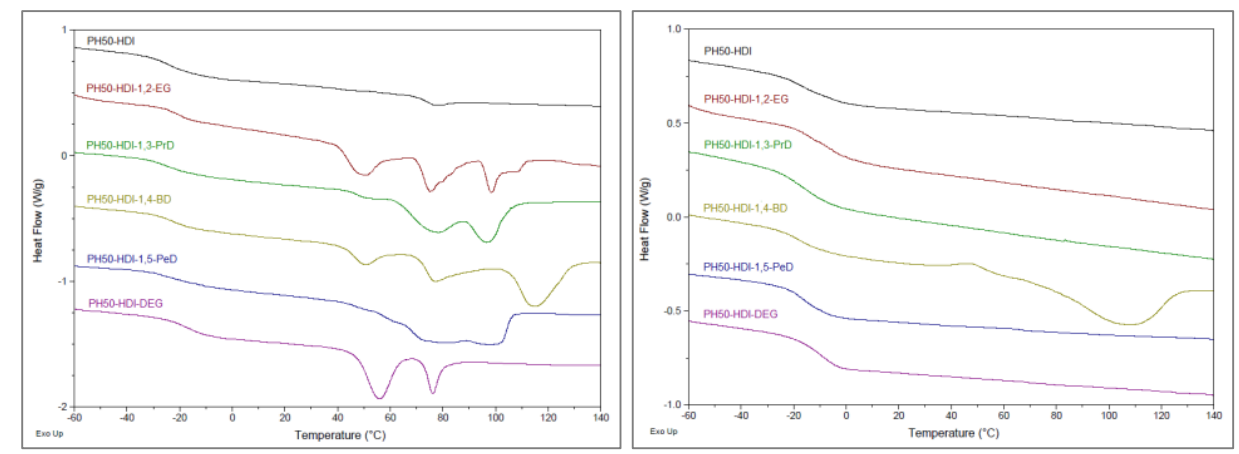

Figure 4 DSC curves of coatings prepared with HDI, first heating cycle (left) and second heating cycle (right)

Formulations prepared with IPDI showed broader glass transition of SS at significantly higher temperatures, varying from $4^{\circ} \mathrm{C}$ to $36^{\circ} \mathrm{C}$ in the first heat cycle and $19^{\circ} \mathrm{C}$ to $36^{\circ} \mathrm{C}$ in the second (Figure 5). The increase of breadth and temperature indicates a larger extent of phase-mixing. The formulation prepared without $\mathrm{CE}$ was found to have the lowest $\mathrm{T}_{\mathrm{g}}$ value. This is possibly due to the smaller HS content of this formulation $(\sim 45 \%$ vs $\sim 52 \%)$ and thus fewer HS-SS interactions in the mixed phase. Otherwise, the length of CE was not found to influence morphology of polymers. The lack of a separate glass transition associated with hard segments suggests a high degree of crystallinity of the polar phase, or more probably, simply better phase-mixing. The smaller size of melting peaks in the first heat cycle and lack of melting peaks in the second cycle indicates a mainly amorphous morphology of SS, caused by the bulky isocyanate preventing crystallisation of SS in the phase-mixed region. 

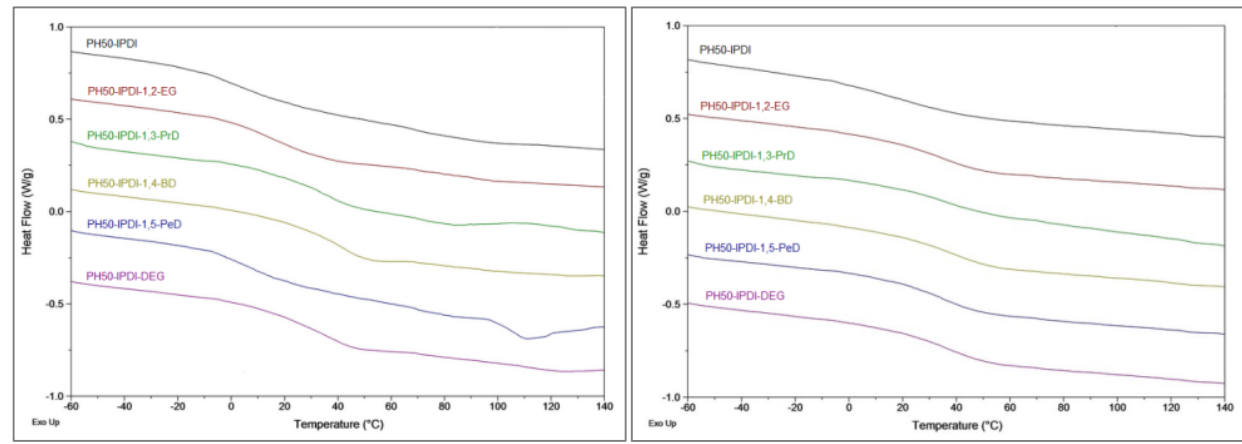

Figure 5 DSC curves of coatings prepared with IPDI,

first heating cycle (left) and second heating cycle (right)

DSC analysis of samples after 12 weeks did not show any significant changes in the $T_{g}$ (see Supplementary Material). However, samples prepared with HDI showed a shift and change in the number of melting peaks, while the more phase-mixed samples prepared without CE or with DEG showed a large increase in enthalpies of melting, indicative of continuous rearrangement of polymer chains enabled by the low $\mathrm{T}_{\mathrm{g}}$ below RT. Samples prepared with IPDI showed minimal changes in the melting temperature and enthalpy, showing high morphological stability of the systems at RT.

\section{ATR FT-IR analysis}

As hydrogen bonding is the driving force of the energetically favourable phase-separation, the morphological composition can be also determined by investigation of $\mathrm{N}-\mathrm{H}$ and $\mathrm{C}=\mathrm{O}$ stretching regions of FTIR (Table 4). H-bonding within HS occurs between the secondary amine and carbonyl groups of urethane. In phase-mixed HS-SS, it is between the secondary amine group of urethane and carbonyl group of polycarbonate. As the strength of H-bonding between HS is stronger than in HS$\mathrm{SS}$, the stretching vibration of $\mathrm{N}-\mathrm{H}$ shows at lower wavenumbers [41,42]. Similarly, carbonyl peaks can be usually split into free, non-H bonded signal at high wavenumber; strongly H-bonded in ordered, phase-separated confirmations at low wavenumbers; and loosely H-bonded in disordered, phase-mixed confirmation between the two signals [43-45]. 
Table 4 Characteristic IR bands for phase-mixed and phase-separated systems [37-40]

\begin{tabular}{llll}
\hline Wavenumber $\left(\mathbf{c m}^{-1}\right)$ & Functional group & Group assignment & Morphology \\
\hline $3500-3400$ & $\mathrm{~N}-\mathrm{H}$ (free) & Urethane & - \\
$3400-3350$ & $\mathrm{~N}-\mathrm{H}$ (bonded) & Urethane & Phase-mixed \\
$3350-3300$ & $\mathrm{~N}-\mathrm{H}$ (bonded) & Urethane & Phase-separated \\
\hline 1743 & $\mathrm{C}=\mathrm{O}$ (free) & Polyol & - \\
$1740-1730$ & $\mathrm{C}=\mathrm{O}$ (bonded) & Polyol & Phase-mixed \\
\hline $1733-1730$ & $\mathrm{C}=\mathrm{O}$ (free) & Urethane & - \\
$1723-1705$ & $\mathrm{C}=\mathrm{O}$ (bonded) & Urethane & Phase-mixed \\
$1700-1683$ & $\mathrm{C}=\mathrm{O}$ (bonded) & Urethane & Phase-separated \\
\hline $1700-1680$ & $\mathrm{C}=\mathrm{O}$ (free) & Urea & - \\
$1660-1635$ & $\mathrm{C}=\mathrm{O}$ (bonded, monodentate) & Urea & Phase-mixed \\
$1616-1627$ & $\mathrm{C}=\mathrm{O}$ (bonded, bidentate) & Urea & Phase-separated \\
\hline $1580-1576$ & $\mathrm{C}-\mathrm{N}, \mathrm{N}-\mathrm{H}$ (bonded, bidentate) & Urea & Phase-separated \\
$1570-1554$ & $\mathrm{C}-\mathrm{N}, \mathrm{N}-\mathrm{H}$ (bonded, monodentate) & Urea & Phase-mixed \\
\hline $1539-1530$ & $\mathrm{C}-\mathrm{N}, \mathrm{N}-\mathrm{H}$ (bonded) & Urethane & Phase-separated \\
$1526-1507$ & $\mathrm{C}-\mathrm{N}, \mathrm{N}-\mathrm{H}$ (bonded) & Urethane & Phase-mixed \\
\hline
\end{tabular}

Both sets of samples show a small amount of non-H-bonded NH (the shoulder at $3500-3400 \mathrm{~cm}^{-1}$ ) suggesting that most $\mathrm{NH}$ groups are involved into H-bonding (Figure 6). The peaks of samples prepared with HDI are sharp, narrow and occur in 3350-3300 $\mathrm{cm}^{-1}$ region, indicating the dominance of HS-HS interactions and hence phase-separation. Samples prepared with IPDI exhibit a broader peak with a more prominent shoulder at $3400-3350 \mathrm{~cm}^{-1}$, indicating the dominance of HS-SS interactions and phase-mixing. This is important as it is these HS-SS interactions that are the drivingforce for the self-healing. Interestingly, samples prepared without CE showed smaller, less sharp peaks at a marginally higher wavenumber, confirming that the presence of CE promotes phaseseparation.
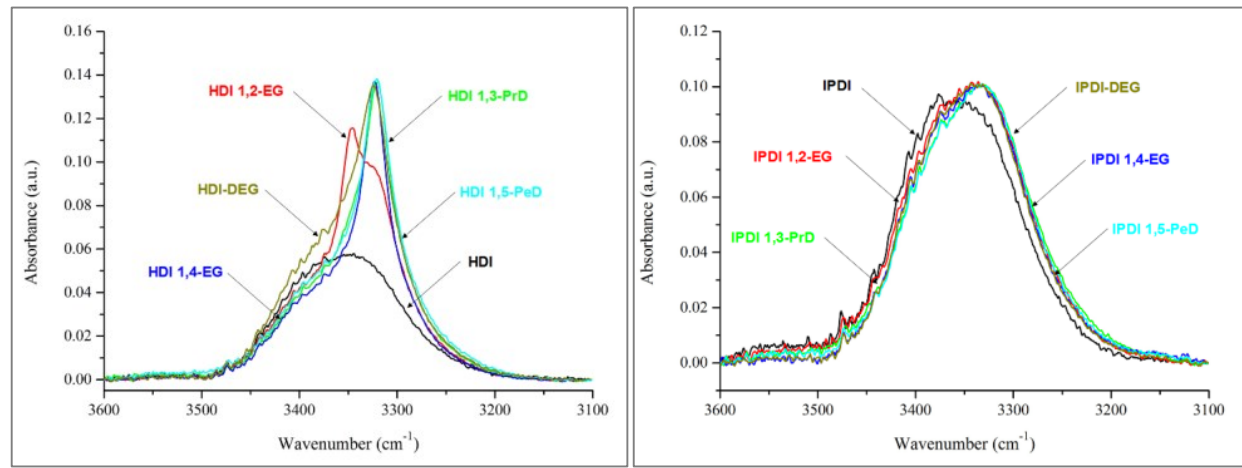

Figure $6 \mathrm{NH}$ region of ATR FT-IR spectra of samples prepared with HDI (left) and IPDI (right) 
In the carbonyl region, the peak at $1743 \mathrm{~cm}^{-1}$ can be assigned to a non-H-bonded $\mathrm{CO}$ stretch of SS, while the peak at $1740-1730 \mathrm{~cm}^{-1}$ shows the loosely H-bonded carbonyl of phase-mixed SS (Figure 7). The peak at $1680 \mathrm{~cm}^{-1}$, associated with HS-HS interactions of urethane groups and phaseseparation, is significantly larger in the spectra of coatings prepared with HDI. The peaks in the $1720-1700 \mathrm{~cm}^{-1}$ region, associated with HS-SS interactions of urethane groups and indicative of phase-mixing, dominate in the spectra of coatings prepared with IPDI. Similar to the NH region of the spectra, samples prepared without CE show significantly smaller peaks in the $1700-1680 \mathrm{~cm}^{-1}$ region, indicating more phase-mixing due to the smaller number of hard segments. Additionally, a small peak at $1635 \mathrm{~cm}^{-1}$, associated with water H-O-H scissoring, was observed, suggesting presence of a small amount of water within the structure, also confirmed by ${ }^{1} \mathrm{H}$ NMR spectroscopy (see Supplementary Material).
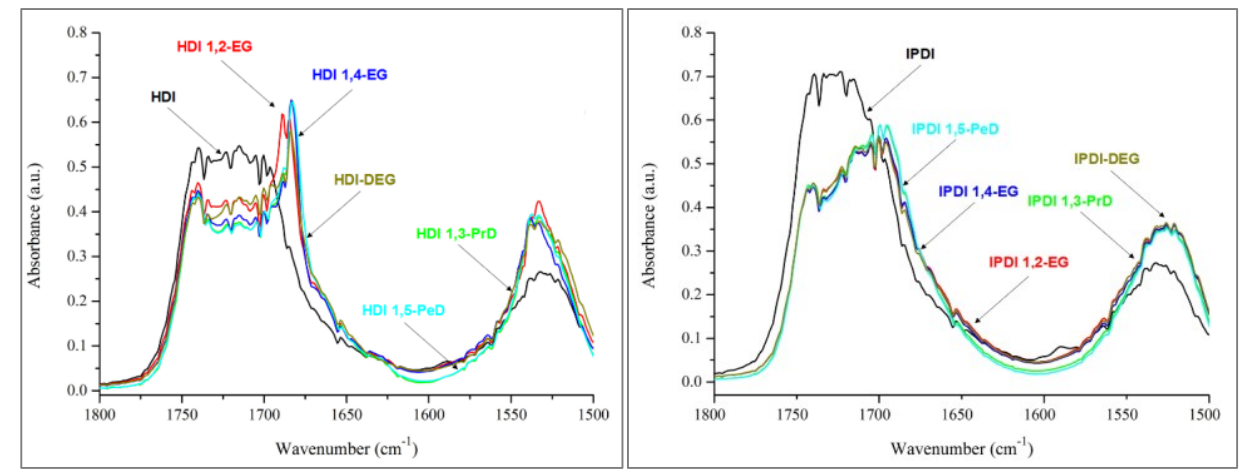

Figure 7 Carbonyl region of ATR FT-IR spectra of samples prepared with HDI (left) and IPDI (right)

In the FTIR spectra taken after 12 weeks, the PH50-HDI and PH50-HDI-DEG samples showed a narrowing and increase of the amine stretch signal. In the carbonyl stretch region an increase of HSHS signal (1700-1680 $\left.\mathrm{cm}^{-1}\right)$ and decrease in HS-SS signal $\left(1720-1700 \mathrm{~cm}^{-1}\right)$ was observed, confirming the increase of phase-separation over time. This leads to bigger domain sizes, higher crystallinity and haze. The spectra of samples prepared with IPDI did not show any significant changes, confirming lower mobility and higher morphological stability of the polymers at RT (see Supplementary Material).

The chemical stability of coatings prepared with IPDI was revealed by the weathering tests. These produced no changes in the ATR FT-IR spectra after 4 weeks of weathering, comparable to 30 weeks outdoor weathering (see Supplementary Material). However, coatings prepared with HDI showed 
significant differences in the spectra, indicative of degradative chemistry. (Figure 8). The increase of absorbance of the peaks at $3600-2400 \mathrm{~cm}^{-1}$ and $1750-1700 \mathrm{~cm}^{-1}$ suggest an oxidative process leading to formation of new carbonyl groups. The new peak appearing at $1600 \mathrm{~cm}^{-1}$ and decrease of the peak at $1540 \mathrm{~cm}^{-1}$ suggests another process, a homolytic bond scission of urethane groups to regenerate isocyanate. A subsequent reaction with atmospheric water can lead to formation of carbamic acid and, in turn, decomposition to amine and $\mathrm{CO}_{2}$, as shown by Kim and Urban [46]. The process is evident only in the HDI-based samples, partly due to the easier access of moisture in these low $\mathrm{T}_{\mathrm{g}}$ coatings, and partly due to the slightly higher reactivity of HDI to water compared to IPDI.

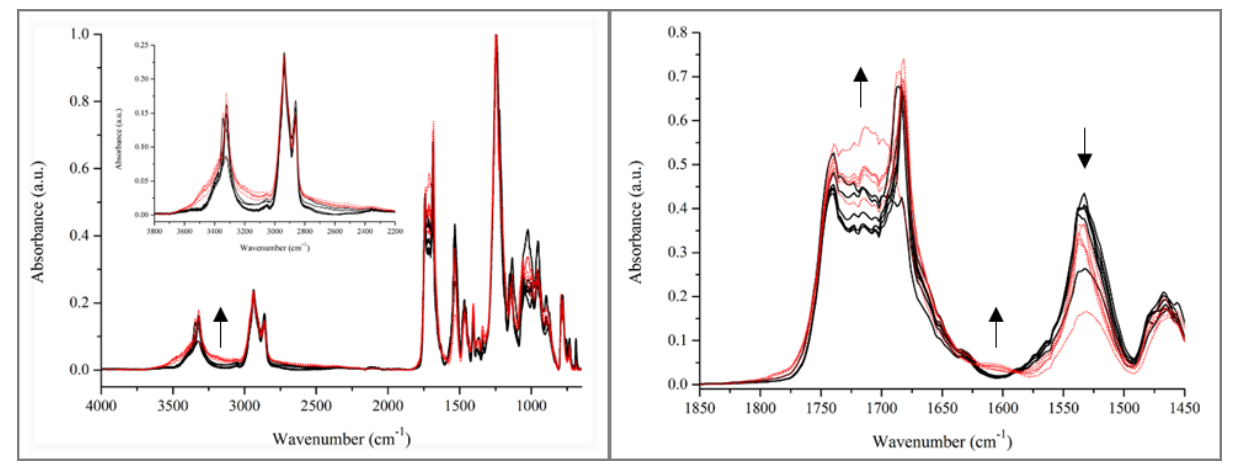

Figure 8 FTIR spectra of aged of HDI-based coatings, black solid line - unweathered, red dotted line - weathered

\section{Evaluation of self-healing properties}

Self-healing behaviour of the coatings is consistent with the model in which the self-healing is driven by the re-establishment of a hydrogen-bonded network [8-11]. SH efficiency tests were performed on all coatings (Figures 9 - 10). The recovery of samples prepared with HDI and 1,3-PrD, 1,4-BD and 1,5-PeD can be neglected due to very high initial haze which renders them unsuitable for optical coatings. Healing of the remaining HDI-based materials occurred readily, both at RT and $60^{\circ} \mathrm{C}$, as the coatings were above the $\mathrm{T}_{\mathrm{g}}$ of the SS phase. The sample prepared without CE showed the highest recovery. This is due to the higher amount of phase-mixing that maximises the HS-SS hydrogen-bonding interactions driving the healing, whilst lowering HS domain sizes and SS crystalline content (which would otherwise act as physical cross-links, limiting mobility). The coating obtained recoveries of up to $150 \%$ at RT and $165 \%$ at $60^{\circ} \mathrm{C}$, thus exhibiting even lower haze after healing than before scratching due to the efficient rearrangement of polymer chains. The coating prepared with DEG, due to the higher amount of phase-separation, had a more limited recovery efficiency of approximately $50 \%$ at RT and $90 \%$ at elevated temperature. The coating 
prepared with 1,2-EG, showing most phase separation, recovered only $25 \%$ of the original haze value at RT and $34 \%$ at elevated temperature. Interestingly, the coating prepared with 1,2-EG showed a small decrease in recovery after the initial healing, which indicates an increase of phaseseparation (and hence haze development) through annealing. The recovery of coatings appeared to be the largest within the first 10 minutes of healing at RT, and within the first 30 minutes at $60^{\circ} \mathrm{C}$.
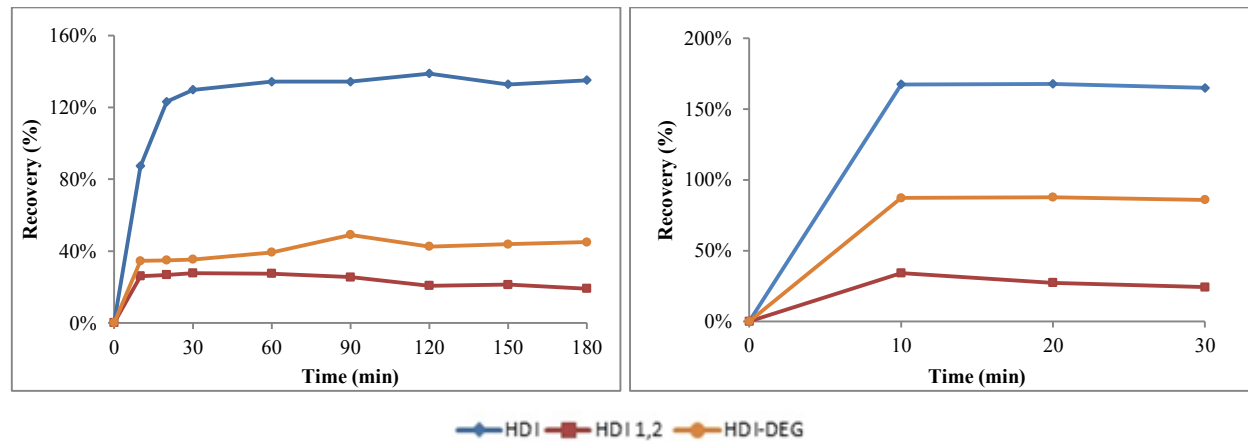

Figure 9 Percentage recovery of samples prepared with HDI at RT (left) and $60^{\circ} \mathrm{C}$ (right)

Coatings prepared with IPDI showed only limited recovery from scratches at RT (Figure 10). As with the HDI-based formulations, the most efficient healing, reaching up to 54\% within 180 minutes, was observed for the coating prepared without CE. Again, this is due to the high amount of phasemixing that maximises the HS-SS hydrogen-bonding interactions that drive the healing process, whilst also lowering the size of HS domains that restrict molecular movement by acting as physical cross-links. Indeed, in the IPDI formulations, the phase-mixing is such that SS crystallisation is also almost wholly supressed, as the DSC data shows. Recovery at RT is more limited than in the HDI formulations due to the higher SS $\mathrm{T}_{\mathrm{g}}$ of the better phase-mixed systems. The least efficient healing, reaching only to $19 \%$, was for the coating prepared with $1,3-\mathrm{PrD}$. The remaining coatings displayed recoveries of between 26 and $32 \%$.

At $60^{\circ} \mathrm{C}$, all the IPDI-based samples showed almost full recovery from damage, reaching $98 \%$ recovery for samples prepared with $\mathrm{CE}$, and $89 \%$ recovery for the coating without CE. The significant improvement of the healing properties at elevated temperatures can be explained by the healing process taking place above the $\mathrm{T}_{\mathrm{g}}$ of SS, allowing the polymer chains to move and rearrange freely. The SH tests repeated after 12 weeks showed identical recovery efficiency, proving that the 
ageing of polymers does not affect the healing properties of the coatings (see Supplementary Material). Figure 11 shows visually, the self-healing of an IPDI-based coating.
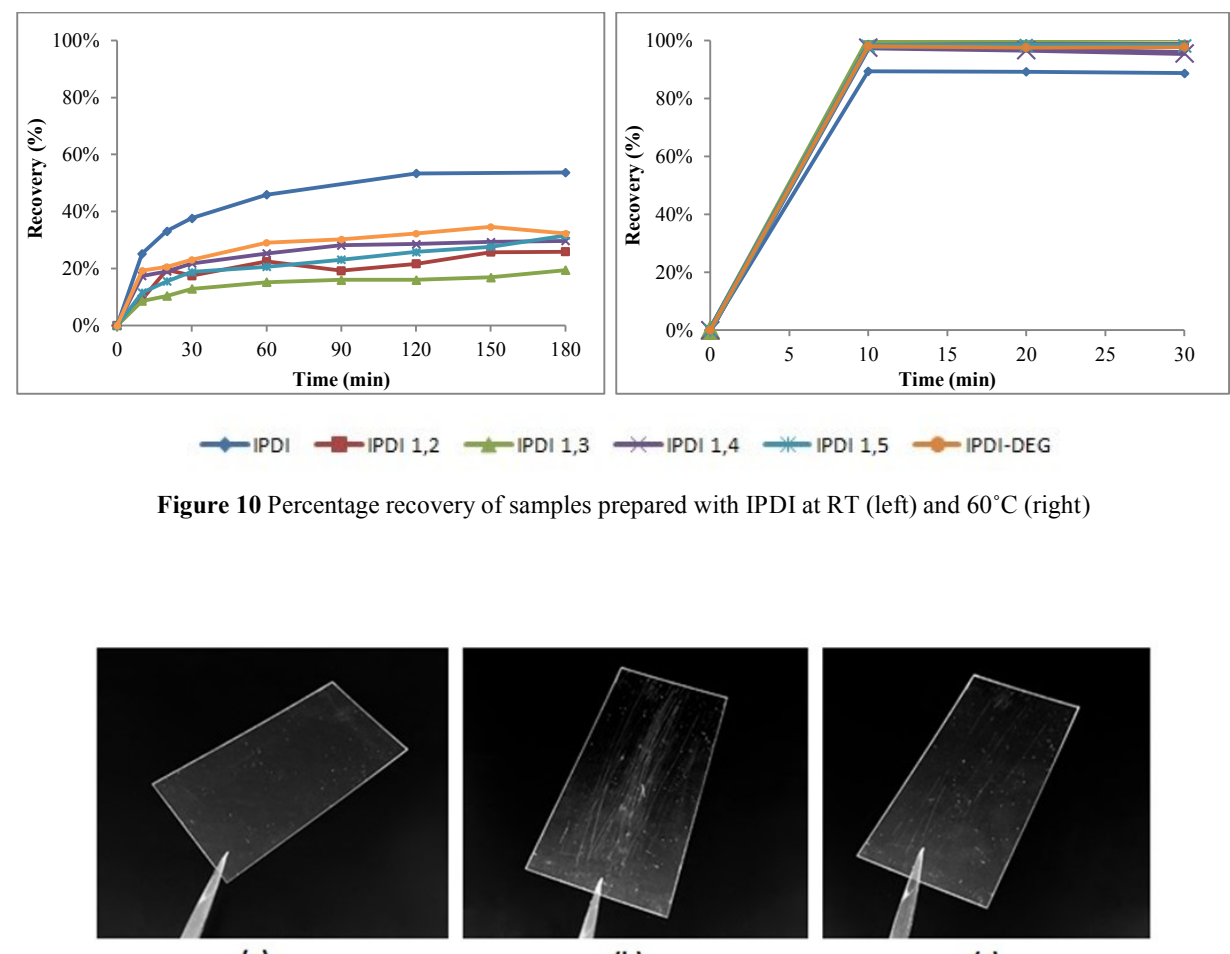

(a)

(b)

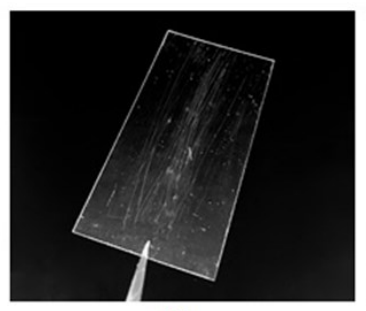

(c)

Figure 11 Recovery of sample PH50/IPDI/1,2-EG at elevated temperature: a) before scratching, haze 0.94,

b) after scratching, haze $6.25, \mathrm{c}$ ) after $10 \mathrm{~min}$ at $60^{\circ} \mathrm{C}$, haze 1.12

Scratching of polymer matrix has been reported to induce covalent bond scission, leading to a decrease of polymer molecular mass in the vicinity of the damage [16]. However, in the case of relatively light scratching of protective coatings, such an effect would be localised on the surface of the polymer and only severely damaged samples would show a change in their overall molecular mass. The fundamental mode of action of our self-healing coatings does not need, therefore, to accommodate the need for re-formation of covalent bonds. Instead, the healing of the scratches is facilitated by molecular motion and driven by the formation of a hydrogen-bonded network in the phase-mixed region of the polymer. Where HS-HS and SS-SS interactions dominate over HS-SS 
interactions, as in the chain-extended HDI formulations, extensive phase separation occurs, reducing relative self-healing efficiency. Phase-separation also induces haze, and IPDI-based formulations, which show good phase-mixing are therefore favoured for high-clarity applications. The phasemixed IPDI-based coatings were found to also had higher $T_{g}$ values. This creates a stable polymer morphology and thus a coating unable to heal at room temperature yet efficiently healing at elevated temperatures above $\mathrm{T}_{\mathrm{g}}$. Small quantities of absorbed moisture, present in such PUs, may be expected to facilitate the healing process through plasticisation but is not a fundamental driver in itself.

\section{Conclusions}

PU coatings prepared with IPDI were found to have a phase-mixed morphology linked to the unsymmetrical and non-planar structure of the isocyanate. This prevents HS crystallisation and phase-separation of the system. HDI-based coatings were more phase-separated, influenced by the linear, symmetrical and planar structure of the isocyanate facilitating HS crystallisation and phaseseparation. Formulations prepared without CE or with DEG as the CE showed increased phasemixing. In HDI-based coatings the increase of $\mathrm{CE}$ length was found to promote crystallinity, phaseseparation and increase of haze caused by light scattering by the HS domains and crystallites (including SS crystals).

It can be concluded that efficiently self-healing, transparent coatings require to have-a non-polar, well phase-mixed morphology, in which the chain mobility and restoration of H-bonds can be accelerated by exceeding the $\mathrm{T}_{\mathrm{g}}$ of SS. Such a morphology can obtained by use of bulky isocyanates such as IPDI with various CE, and partially gained by use of HDI without CE or with short and polar CE such as DEG.

\section{Acknowledgements}

Financial support for this work, access to specialised equipment and sharing expertise from Polaroid Eyewear, the project's industrial collaborator, is greatly acknowledged. 


\section{References}

[1] R.P. Wool, Self-healing materials: a review, Soft Matter. 4 (2008) 400-418.

[2] M. Ardjmand, A.S. Rad, Optimization of Self-Healing Automotive PU Coating Using Desmodure N3800 as Isocyanate and the Different Desmophens as Polyalcohols, Arab. J. Sci. Eng. 38 (2012) 1005-1009.

[3] M. Ionescu, Chemistry and technology of polyols for polyurethanes, 1st ed., Rapra Technology Limited, Shawbury, 2008.

[4] B. Finnigan, D. Martin, P. Halley, R. Truss, K. Campbell, Morphology and properties of thermoplastic polyurethane nanocomposites incorporating hydrophilic layered silicates, Polymer (Guildf). 45 (2004) 2249-2260.

[5] D.Y. Wu, S. Meure, D. Solomon, Self-healing polymeric materials: A review of recent developments, Prog. Polym. Sci. 33 (2008) 479-522.

[6] C. Prisacariu, Structural studies on polyurethane elastomers, in: Polyurethane Elastomers, 1st ed., Springer-Verlag, Wien, 2011: pp. $23-60$.

[7] M. Mechel, Shining prospects for two-component polyurethane clearcoats, Bayer Materials Science, www.bayercoatings.com, accessed August, 2004.

[8] A.W. Bosman, R.P. Sijbesma, E.W. Meijer, Supramolecular polymers at work, Mater. Today. 7 (2004) 34-39.

[9] P. Cordier, F. Tournilhac, C. Soulié-Ziakovic, L. Leibler, Self-healing and thermoreversible rubber from supramolecular assembly, Nature. 451 (2008) 977-980

[10] E.B. Stukalin, L.H. Cai, N.A. Kumar, L. Leibler, M. Rubinstein, Self-healing of unentangled polymer networks with reversible bonds, Macromolecules. 46 (2013) 7525-7541.

[11] F. Herbst, S. Seiffert, W.H. Binder, Dynamic supramolecular poly(isobutylene)s for self-healing materials, Polym. Chem. 3 (2012) 3084 3092.

[12] S. Chen, N. Mahmood, M. Beiner, W.H. Binder, Self-Healing Materials from V- and H-Shaped Supramolecular Architectures, Angew. Chemie - Int. Ed. 54 (2015) 10188-10192.

[13] S. Burattini, H.M. Colquhoun, B.W. Greenland, W. Hayes, A novel self-healing supramolecular polymer system, Faraday Discuss. 143 (2009) 251-264.

[14] S. Burattini, H. Merino, W. Weng, S.J. Rowan, A healable supramolecular polymer blend based on aromatic $\pi-\pi$ stacking and hydrogen bonding interactions, J. Am. Chem. Soc. 132 (2010) 12051-12058.

[15] M. Burnworth, L. Tang, J.R. Kumpfer, A.J. Duncan, F.L. Beyer, G.L. Fiore, S.J. Rowan, C. Weder, Optically healable supramolecular polymers, Nature. 472 (2011) 334-337.

[16] B. Ghosh, K. V. Chellappan, M.W. Urban, UV-initiated self-healing of oxolane-chitosan-polyurethane (OXO-CHI-PUR) networks, J. Mater. Chem. 22 (2012) 16104-16113.

[17] A. Ghosh, D.I. Dimitrov, V.G. Rostiashvili, A. Milchev, T.A. Vilgis, Thermal breakage and self-healing of a polymer chain under tensile stress, J. Chem. Phys. 132 (2010) 1-18.

[18] A.M. Grande, J.C. Bijleveld, S.J. Garcia, S. Van Der Zwaag, A combined fracture mechanical - rheological study to separate the contributions of hydrogen bonds and disulphide linkages to the healing of poly(urea-urethane) networks, Polym. (United Kingdom). 96 (2016) 26-34.

[19] I.M. Pereira, R.L. Oréfice, Study of the morphology exhibited by linear segmented polyurethanes, Macromol. Symp. 299-300 (2011) 190198.

[20] Z.S. Petrovic, Handbook of Polymer Synthesis, 2nd ed., Marcel Dekker, Inc., New York, 2005.

[21] A. Eceiza, M.D. Martin, K. de la Caba, G. Kortaberria, N. Gabilondo, M.A. Corcuera, I. Mondragon, Thermoplastic Polyurethane Elastomers Based on Polycarbonate Diols with different soft segment molecular weight and chemical structure: mechanical and thermal properties, Polym. Eng. Sci. 2 (2008) 297-306.

[22] V. García-Pacios, J.A. Jofre-Reche, V. Costa, M. Colera, J.M. Martín-Martínez, Coatings prepared from waterborne polyurethane dispersions obtained with polycarbonates of 1,6-hexanediol of different molecular weights, Prog. Org. Coatings. 76 (2013) 1484-1493.

[23] Y.M. Lee, J.C. Lee, B.K. Kim, Effect of soft segment length on the properties of polyurethane anionomer dispersion, Polymer (Guildf). 35 (1994) 1095-1099.

[24] S. Sami, E. Yildirim, M. Yurtsever, E. Yurtsever, E. Yilgor, I. Yilgor, G.L. Wilkes, Understanding the influence of hydrogen bonding and diisocyanate symmetry on the morphology and properties of segmented polyurethanes and polyureas: Computational and experimental study, Polym. (United Kingdom). 55 (2014) 4563-4576.

[25] C.M. Gomez, D. Gutierrez, M. Asensio, V. Costa, A. Nohales, Transparent thermoplastic polyurethanes based on aliphatic diisocyanates and polycarbonate diol, J. Elastomers Plast. 49 (2017) 77-95. 
[26] K. Gisselfält, B. Helgee, Effect of soft segment length and chain extender structure on phase separation and morphology in poly(urethane urea)s, Macromol. Mater. Eng. 288 (2003) 265-271.

[27] J. Blackwell, M.R. Nagarajan, T.B. Hoitink, Structure of polyurethane elastomers: effect of chain extender length on the structure of MDI/diol hard segments, Polymer (Guildf). 23 (1982) 950-956.

[28] C.-C. Chang, K.-S. Chen, T.L. Yu, Y.-S. Chen, C.-L. Tsai, Y.-H. Tseng, Phase Segregation of Polyester Based-Polyurethanes, Polym. J. 31 (1999) 1205-1210.

[29] Y.J. Kim, P.H. Huh, B.K. Kim, Synthesis of self-healing polyurethane urea-based supramolecular materials, J. Polym. Sci. Part B Polym. Phys. 53 (2015) 468-474.

[30] Y. González-García, J.M.C. Mol, T. Muselle, I. De Graeve, G. Van Assche, G. Scheltjens, B. Van Mele, H. Terryn, A combined mechanical, microscopic and local electrochemical evaluation of self-healing properties of shape-memory polyurethane coatings, Electrochim. Acta. 56 (2011) 9619-9626.

[31] P. Du, M. Wu, X. Liu, Z. Zheng, X. Wang, T. Joncheray, Y. Zhang, Diels-Alder-based crosslinked self-healing polyurethane/urea from polymeric methylene diphenyl diisocyanate, J. Appl. Polym. Sci. 131 (2014) 1-7.

[32] G. Rivero, L.-T.T. Nguyen, X.K.D. Hillewaere, F.E. Du Prez, One-Pot Thermo-Remendable Shape Memory Polyurethanes, Macromolecules. 47 (2014) 2010-2018.

[33] D. Dieterich, Aqueous emulsions, dispersions and solutions of polyurethanes; synthesis and properties, Prog. Org. Coatings. 9 (1981) 281340 .

[34] M.J. O'Sickey, Characterization of Structure-Property Relationships of Poly(urethane-urea)s for Fiber Applications, Doctoral Dissertation, Virginia Polytechnic Institute and State University, 2002.

[35] F.C. Stehling, C.S. Speed, L. Westerman, Causes of haze of low-density polyethylene blown films, Macromolecules. 14 (1981) 698-708

[36] E. Andreassen, A. Larsen, K. Nord-Varhaug, M. Skar, H. Emptysd, Haze of polyethylene films - Effects of material parameters and clarifying agents, Polym. Eng. Sci. 42 (2002) 1082-1097.

[37] E. Princi, S. Vicini, K. Castro, D. Capitani, N. Proietti, L. Mannina, On the micro-phase separation in waterborne polyurethanes, Macromol. Chem. Phys. 210 (2009) 879-889.

[38] E. Ylgor, I. Ylgor, E. Yurtsever, Hydrogen bonding and polyurethane morphology. I. Quantum mechanical calculations of hydrogen bond energies and vibrational spectroscopy of model compounds, Polymer (Guildf). 43 (2002) 6551-6559.

[39] C.S.P. Sung, N.S. Schneider, Infrared Studies of Hydrogen Bonding in Toluene Diisocyanate Based Polyurethanes, Macromolecules. 8 (1974) 68-73.

[40] A.G. Strikovsky, IR-Spectroscopy of Hydrogen Bond as a Method of Analytical Determination of Physical Network in Poly(ether urethane)s, Macromol. Symp. 94 (1995) 181-188.

[41] S.M. Cakić, M. Špírková, I.S. Ristić, J.K. B-Simendić, M. M-Cincović, R. Porẹba, The waterborne polyurethane dispersions based on polycarbonate diol: Effect of ionic content, Mater. Chem. Phys. 138 (2013) 277-285.

[42] H.S. Lee, Y.K. Wang, S.L. Hsu, Spectroscopic analysis of phase separation behavior of model polyurethanes, Macromolecules. 20 (1987) 2089-2095

[43] M. Špírková, J. Pavličević, A. Strachota, R. Poreba, O. Bera, L. Kaprálková, J. Baldrian, M. Šlouf, N. Lazić, J. Budinski-Simendić, Novel polycarbonate-based polyurethane elastomers: Composition-property relationship, Eur. Polym. J. 47 (2011) 959-972.

[44] S. Pongkitwitoon, R. Hernández, J. Weksler, A. Padsalgikar, T. Choi, J. Runt, Temperature dependent microphase mixing of model polyurethanes with different intersegment compatibilities, Polymer (Guildf). 50 (2009) 6305-6311.

[45] E. Cipriani, M. Zanetti, V. Brunella, L. Costa, P. Bracco, Thermoplastic polyurethanes with polycarbonate soft phase: Effect of thermal treatment on phase morphology, Polym. Degrad. Stab. 97 (2012) 1794-1800.

[46] H. Kim, M.W. Urban, Molecular level chain scission mechanisms of epoxy and urethane polymeric films exposed to UV/H2O. Multidimensional spectroscopic studies, Langmuir. 16 (2000) 5382-5390. 
Supplementary information 
SI Table 1. Amounts of PU starting materials

\begin{tabular}{|c|c|c|c|c|c|c|c|c|c|c|}
\hline \multirow{2}{*}{ Polyurethane } & \multicolumn{2}{|c|}{ PH50 } & \multicolumn{3}{|c|}{ Isocyanate } & \multicolumn{2}{|c|}{ DMPA } & \multicolumn{3}{|c|}{$\underline{\mathrm{CE}}$} \\
\hline & mmol & g & mmol & $\mathrm{g}$ & $\underline{\mathrm{ml}}$ & mmol & - g & mmol & $\mathrm{g}$ & $\underline{\mathrm{ml}}$ \\
\hline PH50-HDI & 20.0 & 10.0 & 25.0 & 4.20 & 4.02 & 5.0 & 0.67 & $=$ & $=$ & 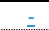 \\
\hline PH50-HDI-EG & 20.0 & 10.0 & 40.0 & 6.73 & 6.43 & 5.0 & 0.67 & 15.0 & $\underline{0.93}$ & 0.84 \\
\hline PH50-HDI-PrD & 20.0 & 10.0 & 40.0 & 6.73 & 6.43 & 5.0 & 0.67 & $\overline{15.0}$ & 1.14 & 1.06 \\
\hline PH50-HDI-BD & 20.0 & 10.0 & 40.0 & 6.73 & 6.43 & 5.0 & 0.67 & 15.0 & 1.35 & 1.33 \\
\hline PH50-HDI-PeD & 20.0 & 10.0 & 40.0 & 6.73 & 6.43 & 5.0 & 0.67 & 15.0 & 1.56 & 1.57 \\
\hline PH50-HDI-DEG & 20.0 & 10.0 & 40.0 & 6.73 & 6.43 & 5.0 & 0.67 & 15.0 & 1.60 & 1.35 \\
\hline PH50-IPDI & 20.0 & 10.0 & 25.0 & 5.55 & 5.24 & 5.0 & 0.67 & $=$ & $=$ & zin \\
\hline PH50-IPDI-EG & 20.0 & 10.0 & 40.0 & 8.89 & 8.39 & 5.0 & 0.67 & 15.0 & 0.93 & 0.84 \\
\hline PH50-IPDI-PrD & $\underline{20.0}$ & 10.0 & $\underline{40.0}$ & 8.89 & 8.39 & $\underline{5.0}$ & $\underline{0.67}$ & 15.0 & 1.14 & 1.06 \\
\hline PH50-IPDI-BD & 20.0 & 10.0 & 40.0 & 8.89 & 8.39 & 5.0 & 0.67 & 15.0 & 1.35 & 1.33 \\
\hline PH50-IPDI-PeD & 20.0 & 10.0 & 40.0 & 8.89 & 8.39 & 5.0 & 0.67 & 15.0 & 1.56 & 1.57 \\
\hline PH50-IPDI-DEG & 20.0 & 10.0 & 40.0 & 8.89 & 8.39 & 5.0 & 0.67 & 15.0 & 1.60 & 1.35 \\
\hline
\end{tabular}

$\underline{\text { SI Table 2. Solid content - mass balances }}$

\begin{tabular}{|c|c|c|c|c|c|c|}
\hline Polyurethane & $\frac{\text { Pan mass }}{\text { (mg) }}$ & $\frac{\text { Pan }+ \text { dispersion mass }}{(\mathrm{mg})}$ & $\frac{\text { Pan + solid mass }}{\text { (mg) }}$ & $\frac{\text { Dispersion mass }}{(\mathrm{mg})}$ & $\frac{\text { Solid Mass }}{\text { (mg) }}$ & $\%$ wt \\
\hline \multirow{3}{*}{ PH50-HDI } & 39.57 & 55.07 & 44.69 & 15.50 & 5.12 & $33.0 \%$ \\
\hline & 39.47 & $\overline{62.45}$ & $\overline{46.99}$ & $\overline{22.98}$ & $\overline{7.52}$ & $32.7 \%$ \\
\hline & 39.51 & $\overline{63.48}$ & $\overline{47.38}$ & 23.97 & $\overline{7.87}$ & $32.8 \%$ \\
\hline \multirow{3}{*}{$\underline{\text { PH50-HDI-EG }}$} & 39.64 & $\overline{67.36}$ & $\overline{47.44}$ & 27.72 & 7.80 & $28.1 \%$ \\
\hline & $\underline{39.65}$ & $\overline{57.50}$ & $\overline{44.40}$ & $\underline{17.85}$ & $\underline{4.75}$ & $\overline{26.6 \%}$ \\
\hline & $\underline{39.72}$ & $\underline{63.58}$ & $\underline{46.16}$ & $\underline{23.86}$ & $\overline{6.44}$ & $\underline{27.0 \%}$ \\
\hline \multirow{3}{*}{$\underline{\text { PH50-HDI-PrD }}$} & $\underline{39.26}$ & $\underline{66.40}$ & $\underline{43.56}$ & 27.14 & 4.30 & $15.8 \%$ \\
\hline & $\underline{39.32}$ & $\underline{62.09}$ & 42.90 & 22.77 & $\underline{3.58}$ & $15.7 \%$ \\
\hline & $\underline{39.38}$ & $\underline{61.23}$ & 42.81 & $\underline{21.85}$ & $\underline{3.43}$ & $15.7 \%$ \\
\hline \multirow{3}{*}{$\underline{\text { PH50-HDI-BD }}$} & $\underline{39.68}$ & 61.69 & 45.80 & 22.01 & 6.12 & $27.8 \%$ \\
\hline & 39.77 & 70.86 & 48.22 & $\underline{31.09}$ & 8.45 & $27.2 \%$ \\
\hline & 39.56 & 68.54 & $\overline{47.51}$ & 28.98 & 7.95 & $27.4 \%$ \\
\hline \multirow{3}{*}{ PH50-HDI-PeD } & 39.53 & $\underline{53.24}$ & 41.15 & 13.71 & 1.62 & $11.8 \%$ \\
\hline & $\underline{39.43}$ & $\underline{56.27}$ & 41.42 & 16.84 & 1.99 & $11.8 \%$ \\
\hline & 39.58 & 59.87 & 42.08 & $\underline{20.29}$ & 2.50 & $12.3 \%$ \\
\hline \multirow{3}{*}{ PH50-HDI-DEG } & 39.93 & 71.58 & 48.61 & 31.65 & 8.68 & $27.4 \%$ \\
\hline & $\underline{39.88}$ & $\underline{58.11}$ & 45.02 & 18.23 & $\underline{5.14}$ & $28.2 \%$ \\
\hline & $\underline{38.98}$ & 57.68 & 43.97 & 18.70 & 4.99 & $26.7 \%$ \\
\hline \multirow{3}{*}{ PH50-IPDI } & $\underline{39.71}$ & $\underline{58.69}$ & 45.28 & 18.98 & 5.57 & $29.3 \%$ \\
\hline & $\underline{39.76}$ & $\underline{59.10}$ & $\underline{45.45}$ & 19.34 & $\underline{5.69}$ & $29.4 \%$ \\
\hline & $\underline{39.78}$ & $\underline{57.64}$ & $\underline{45.03}$ & $\underline{17.86}$ & $\underline{5.25}$ & $29.4 \%$ \\
\hline \multirow{3}{*}{ PH50-IPDI-EG } & $\underline{39.89}$ & $\underline{61.65}$ & 44.89 & 21.76 & 5.00 & $23.0 \%$ \\
\hline & $\underline{39.58}$ & $\underline{66.55}$ & 45.82 & $\underline{26.97}$ & 6.24 & $23.1 \%$ \\
\hline & $\underline{39.67}$ & $\underline{62.25}$ & $\underline{45.02}$ & $\underline{22.58}$ & $\underline{5.35}$ & $23.7 \%$ \\
\hline \multirow{3}{*}{ PH50-IPDI-PrD } & $\underline{39.33}$ & $\underline{59.38}$ & 46.45 & 20.05 & 7.12 & $35.5 \%$ \\
\hline & $\underline{39.51}$ & $\underline{62.55}$ & $\underline{43.66}$ & 23.04 & 4.15 & $18.0 \%$ \\
\hline & 39.54 & $\underline{65.89}$ & $\underline{46.45}$ & $\underline{26.35}$ & 6.91 & $26.2 \%$ \\
\hline \multirow{3}{*}{ PH50-IPDI-BD } & $\underline{39.78}$ & $\underline{54.13}$ & 43.37 & 14.35 & $\underline{3.59}$ & $25.0 \%$ \\
\hline & $\underline{40.03}$ & $\underline{61.48}$ & $\underline{45.08}$ & 21.45 & $\underline{5.05}$ & $23.5 \%$ \\
\hline & $\underline{39.87}$ & $\underline{60.58}$ & $\underline{44.89}$ & $\underline{20.71}$ & $\underline{5.02}$ & $24.2 \%$ \\
\hline \multirow{3}{*}{ PH50-IPDI-PeD } & $\underline{39.25}$ & $\underline{60.41}$ & $\underline{46.23}$ & $\underline{21.16}$ & $\underline{6.98}$ & $33.0 \%$ \\
\hline & 39.50 & 60.24 & 44.01 & 20.74 & $\underline{4.51}$ & $21.7 \%$ \\
\hline & $\underline{38.99}$ & $\underline{61.85}$ & $\underline{45.26}$ & $\underline{22.86}$ & $\underline{6.27}$ & $\underline{27.4 \%}$ \\
\hline PH50-IPDI-DEG & 40.12 & 70.52 & 47.19 & 30.40 & 7.07 & $23.3 \%$ \\
\hline
\end{tabular}




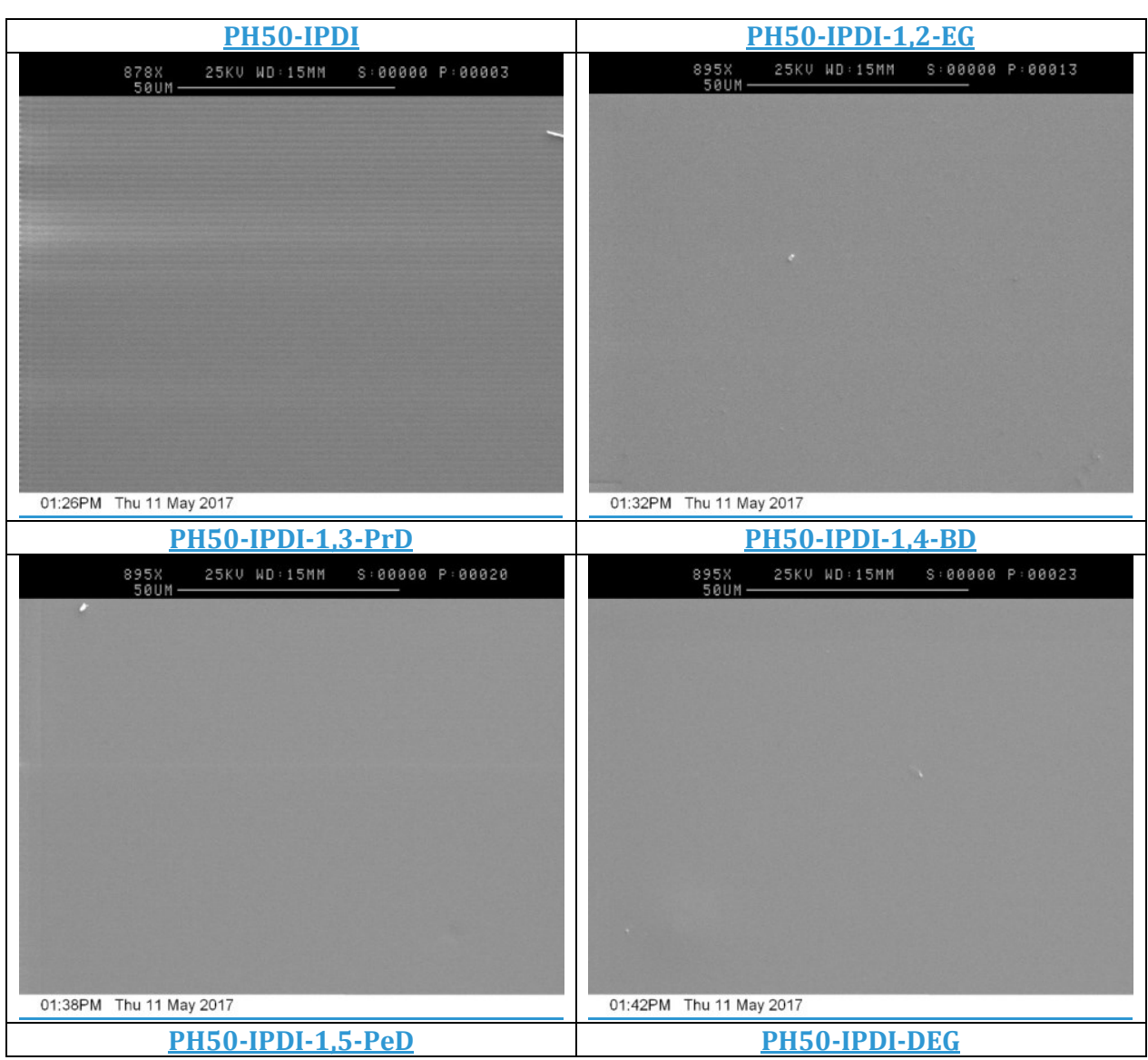




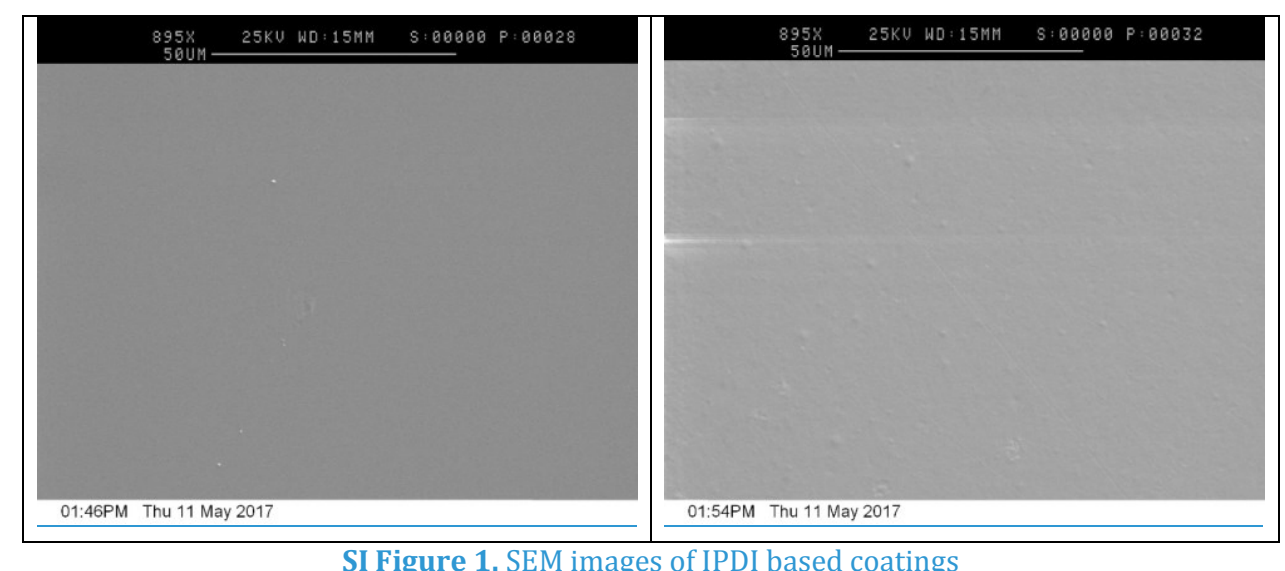

$\underline{\text { SI Figure 1. SEM images of IPDI based coatings }}$ 
SI Table 3. DSC characterisation data

\begin{tabular}{|c|c|c|c|c|c|c|c|c|c|c|c|c|}
\hline \multirow{3}{*}{ Polvurethane } & \multicolumn{4}{|c|}{$\underline{T_{g}\left({ }^{\circ} \mathrm{C}\right)}$} & \multicolumn{4}{|c|}{$\mathrm{T}_{\mathrm{m}}\left({ }^{\circ} \mathrm{C}\right)$} & \multicolumn{4}{|c|}{$\Delta \mathrm{H}_{\mathrm{m}}(\mathrm{I} / \mathrm{mol})$} \\
\hline & \multicolumn{2}{|c|}{$\underline{0 \text { weeks }}$} & \multicolumn{2}{|c|}{12 weeks } & \multicolumn{2}{|c|}{$\underline{0 \text { weeks }}$} & \multicolumn{2}{|c|}{12 weeks } & \multicolumn{2}{|c|}{$\underline{0 \text { weeks }}$} & \multicolumn{2}{|c|}{12 weeks } \\
\hline & Heat 1 & Heat 2 & Heat 1 & $\underline{\text { Heat } 2}$ & $\underline{\text { Heat } 1}$ & $\underline{\text { Heat } 2}$ & Heat 1 & Heat 2 & Heat 1 & Heat 2 & $\underline{\text { Heat } 1}$ & $\underline{\text { Heat } 2}$ \\
\hline PH50-HDI & -22.1 & -14.2 & -18.7 & -13.2 & 76.9 & $=$ & 57.8 & $=$ & 1.8 & $=$ & 11.0 & \\
\hline PH50-HDI-EG & $\underline{-20.6}$ & $\underline{-8.4}$ & $\underline{-16.0}$ & $\underline{-7.0}$ & $\begin{array}{r}\frac{49.3}{74.9} \\
\underline{98.4} \\
108.5 \\
\end{array}$ & $=$ & $\underline{\frac{60.4}{84.6}}$ & $=$ & $\underline{29.4}$ & $=$ & $\underline{29.6}$ & $=$ \\
\hline PH50-HDI-PrD & $\underline{-21.3}$ & -10.6 & $\underline{-21.3}$ & $\underline{-13.0}$ & $\underline{\underline{64.0}}$ & $=$ & $\frac{50.3}{\frac{69.4}{93.1}}$ & $=$ & $\underline{35.6}$ & $=$ & $\underline{35.5}$ & $=$ \\
\hline PH50-HDI-BD & -22.0 & $\underline{-15.3}$ & -20.9 & -16.6 & $\frac{50.5}{\underline{77.4}}$ & $\underline{105.9}$ & $\underline{61.3}$ & $\underline{108.9}$ & 41.2 & $\underline{21.0}$ & $\underline{39.4}$ & $\underline{22.1}$ \\
\hline PH50-HDI-PeD & $\underline{-21.3}$ & $\underline{-16.6}$ & $\underline{-22.9}$ & -15.9 & $\underline{55.4}$ & $=$ & $\frac{51.3}{84.5}$ & $=$ & $\underline{36.0}$ & $=$ & $\underline{37.7}$ & $=$ \\
\hline PH50-HDI-DEG & $\underline{-16.9}$ & -10.7 & -17.6 & $\frac{-9.6}{2}$ & $\begin{array}{l}55.7 \\
76.3 \\
\end{array}$ & $=$ & $\underline{59.5}$ & $=$ & $\underline{18.2}$ & $=$ & $\underline{26.0}$ & $=$ \\
\hline PH50-IPDI & 4.2 & 19.2 & 19.5 & 23.0 & 94.6 & $=$ & $=$ & $=$ & 3.7 & $=$ & $=$ & $=$ \\
\hline PH50-IPDI-EG & 16.6 & 31.4 & 30.2 & 32.2 & 97.9 & $=$ & 94.8 & $=$ & 2.3 & - & $\underline{1.1}$ & $=$ \\
\hline PH50-IPDI-PrD & 30.6 & 33.1 & 24.1 & 32.8 & 83.7 & $=$ & 80.0 & $=$ & 2.8 & $=$ & 5.6 & $=$ \\
\hline PH50-IPDI-BD & 35.8 & 35.1 & 32.3 & 30.5 & 98.8 & $=$ & $=$ & $=$ & 2.3 & $=$ & $=$ & $=$ \\
\hline PH50-IPDI-PeD & 7.4 & 32.0 & 22.4 & 30.7 & 109.7 & $=$ & 88.5 & $=$ & 5.8 & $=$ & 3.8 & $=$ \\
\hline PH50-IPDI-DEG & 28.2 & 35.7 & 37.0 & 36.4 & 123.3 & $=$ & 107.0 & $=$ & 1.0 & $=$ & 3.0 & $=$ \\
\hline
\end{tabular}
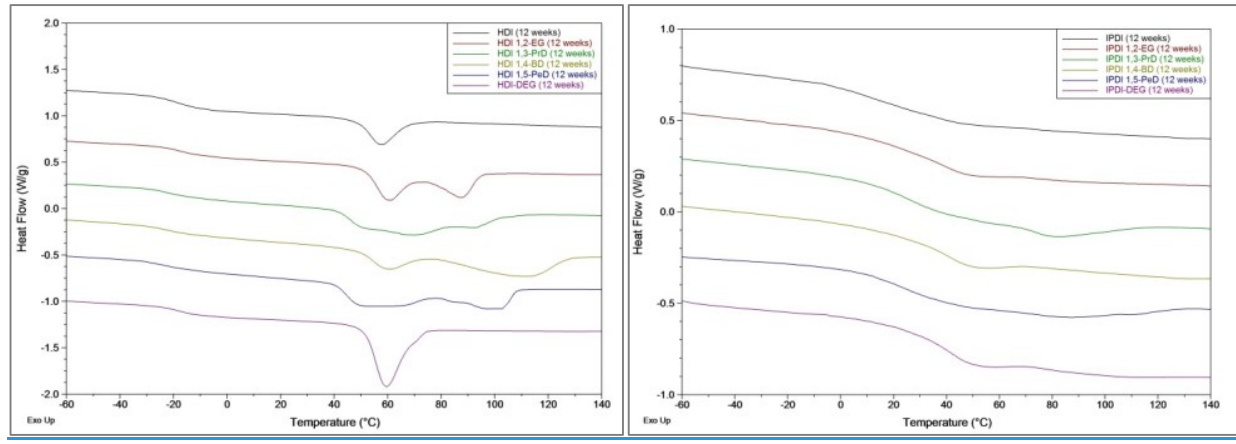

SI Figure 2. DSC curves of coatings tested after 12 weeks, first heat cycle HDI-based samples (left) and IPDI-based samples (right) 


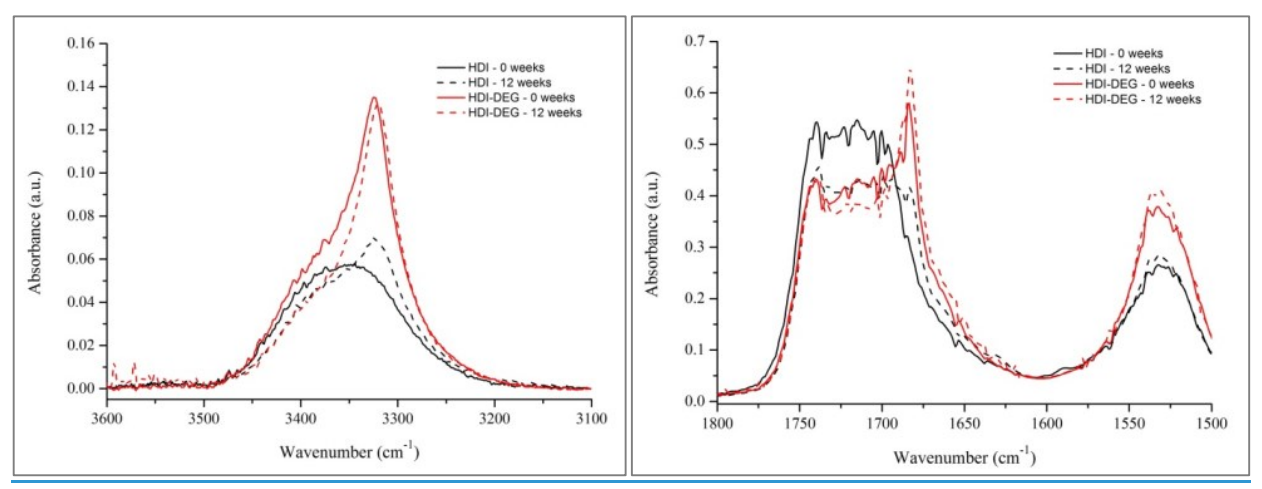

SI Figure 3. ATR-FTIR spectra of samples prepared with HDI, NH region (left) and carbonyl region (right) 


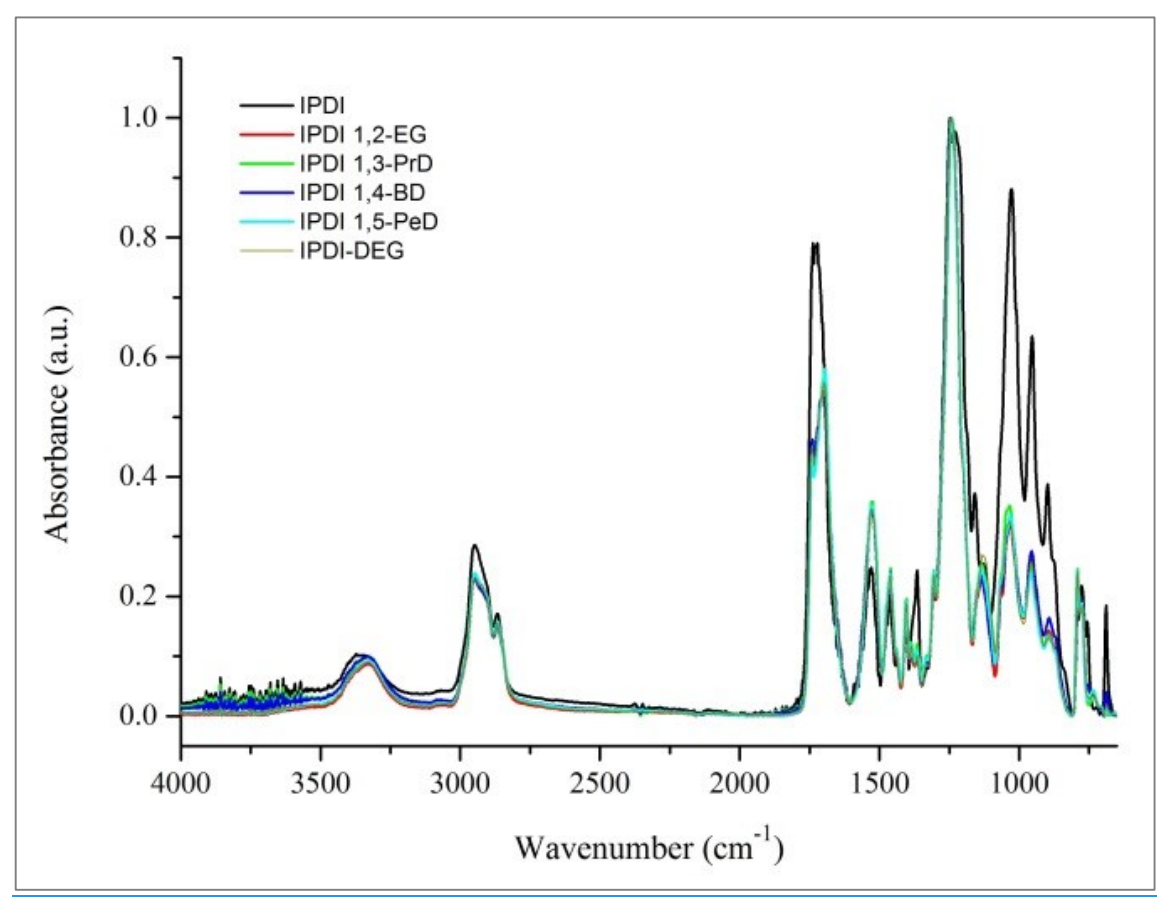

SI Figure 4 ATR FT-IR spectra of HDI based coatings before weathering 


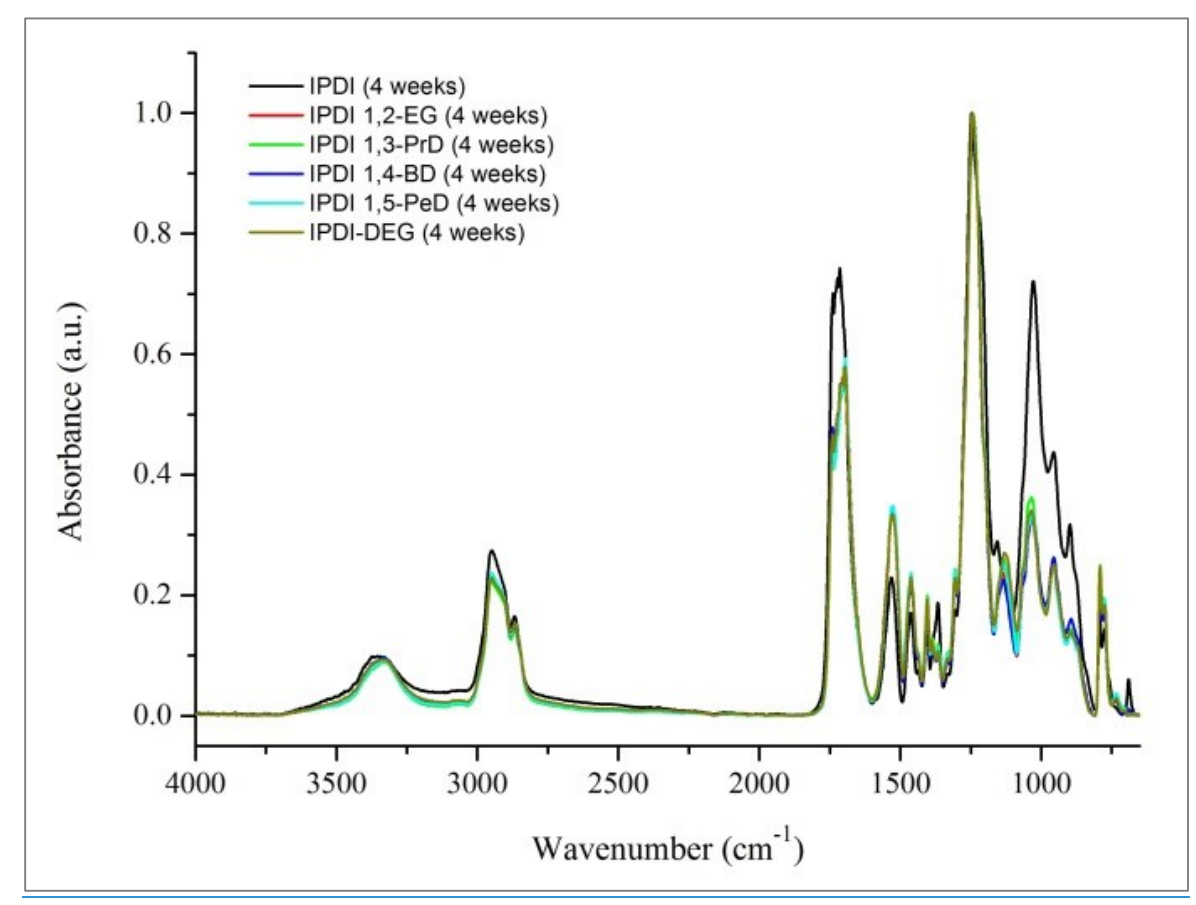

SI Figure 5 ATR FT-IR spectra of HDI based coatings after 4 weeks of weathering 
$\underline{\text { SI Table } 4 \text { Haze values of coatings healed at room temperature }}$

\begin{tabular}{|c|c|c|c|c|c|c|c|c|c|c|}
\hline Polyurethane & $\frac{\underline{\text { Haze }}}{\text { initia }} \frac{1}{\underline{l}}$ & $\frac{\begin{array}{c}\frac{\text { Haze }}{\text { after }} \\
\text { scratchin }\end{array}}{\mathrm{g}}$ & $\begin{array}{c}\frac{\underline{\text { Haze }}}{\frac{10 \mathrm{~min}}{\text { healin }}} \\
\mathrm{g}\end{array}$ & $\begin{array}{c}\frac{\underline{\text { Haze }}}{\frac{20 \mathrm{~min}}{\text { healin }}} \\
\mathrm{g}\end{array}$ & $\begin{array}{l}\frac{\underline{\text { Haze }}}{\frac{30 \mathrm{~min}}{\text { healin }}} \\
\mathrm{g}\end{array}$ & $\begin{array}{l}\frac{\underline{\text { Haze }}}{\frac{60 \mathrm{~min}}{\text { healin }}} \\
\mathrm{g}\end{array}$ & $\begin{array}{l}\frac{\underline{\text { Haze }}}{\frac{90 \mathrm{~min}}{\text { healin }}} \\
\mathrm{g}\end{array}$ & 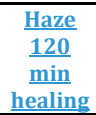 & $\begin{array}{c}\frac{\text { Haze }}{\underline{150}} \\
\underline{\min } \\
\underline{\text { healing }}\end{array}$ & $\begin{array}{l}\frac{\text { Haze }}{180} \\
\underline{\underline{\text { min }}} \\
\underline{\text { healing }}\end{array}$ \\
\hline PH50-HDI & 1.08 & 1.53 & 1.14 & 0.98 & 0.95 & 0.93 & 0.93 & 0.91 & 0.94 & 0.93 \\
\hline PH50-HDI-EG & $\overline{0.33}$ & 1.37 & $\overline{1.10}$ & $\overline{1.09}$ & $\overline{1.08}$ & 1.09 & $\overline{1.11}$ & 1.16 & 1.15 & 1.17 \\
\hline PH50-HDI-PrD & $\overline{34.83}$ & 26.77 & 25.13 & $\overline{25.03}$ & $\overline{25.03}$ & $\overline{24.97}$ & $\overline{24.87}$ & 24.90 & $\overline{24.83}$ & 24.67 \\
\hline PH50-HDI-BD & 69.00 & 65.60 & 65.70 & 65.60 & 65.60 & 65.67 & 65.73 & 65.67 & 65.70 & 65.97 \\
\hline PH50-HDI-PeD & 92.93 & $\underline{92.20}$ & 92.20 & 92.07 & 92.13 & 92.43 & 92.20 & 92.23 & 92.20 & 92.23 \\
\hline PH50-HDI-DEG & 0.45 & 1.28 & 1.00 & 0.99 & 0.99 & 0.96 & 0.88 & $\underline{0.93}$ & 0.92 & 0.91 \\
\hline PH50-IPDI & 0.21 & 6.64 & 5.02 & 4.51 & 4.22 & 3.69 & $=$ & $\underline{3.21}$ & $=$ & $\underline{3.18}$ \\
\hline PH50-IPDI-EG & $\underline{0.22}$ & $\underline{2.83}$ & 2.59 & 2.32 & $\underline{2.38}$ & 2.25 & 2.33 & $\underline{2.27}$ & $\underline{2.16}$ & $\underline{2.16}$ \\
\hline $\begin{array}{l}\text { PH50-IPDI- } \\
\text { PrD }\end{array}$ & $\overline{0.44}$ & $\underline{16.23}$ & $\overline{14.87}$ & $\underline{14.60}$ & $\overline{14.20}$ & $\overline{13.83}$ & $\underline{13.70}$ & $\underline{13.70}$ & $\overline{13.57}$ & $\underline{13.17}$ \\
\hline PH50-IPDI-BD & $\underline{0.44}$ & 4.17 & 3.52 & $\underline{3.46}$ & $\underline{3.36}$ & $\underline{3.23}$ & $\underline{3.12}$ & $\underline{3.11}$ & $\underline{3.08}$ & $\underline{3.07}$ \\
\hline $\begin{array}{l}\text { PH50-IPDI- } \\
\text { PeD }\end{array}$ & $\underline{0.60}$ & 8.86 & 7.90 & 7.58 & 7.31 & $\underline{7.16}$ & 6.95 & 6.73 & 6.58 & 6.25 \\
\hline $\begin{array}{l}\text { PH50-IPDI- } \\
\text { DEG }\end{array}$ & $\underline{0.33}$ & $\underline{4.36}$ & $\underline{3.58}$ & $\underline{3.53}$ & $\underline{3.43}$ & $\underline{3.19}$ & $\underline{3.14}$ & $\underline{3.06}$ & $\underline{2.96}$ & $\underline{3.06}$ \\
\hline
\end{tabular}

SI Table 5 Haze values of coatings healed at $60^{\circ} \mathrm{C}$

\begin{tabular}{|c|c|c|c|c|c|}
\hline Polyurethane & $\underline{\text { Haze }}$ & $\begin{array}{c}\begin{array}{c}\text { Haze } \\
\underline{\text { after }} \\
\text { scratching }\end{array} \\
\underline{\underline{y}}\end{array}$ & $\begin{array}{c}\underline{\text { Haze }} \\
\underline{10 \mathrm{~min}} \\
\underline{\text { healing }}\end{array}$ & $\begin{array}{c}\underline{\underline{\text { Haze }}} \\
\underline{\underline{20 \mathrm{~min}}} \\
\underline{\underline{\text { healing }}}\end{array}$ & $\begin{array}{c}\underline{\underline{\text { Haze }}} \\
\underline{30 \mathrm{~min}} \\
\underline{\text { healing }}\end{array}$ \\
\hline PH50-HDI & 1.88 & $\underline{3.15}$ & $\underline{1.02}$ & 1.02 & $\underline{1.05}$ \\
\hline PH50-HDI-EG & $\underline{0.47}$ & 1.44 & $\underline{1.11}$ & 1.18 & $\underline{1.21}$ \\
\hline PH50-HDI-PrD & 37.73 & 32.40 & 30.97 & 30.83 & 30.67 \\
\hline PH50-HDI-BD & 68.73 & $\underline{64.90}$ & $\underline{64.93}$ & 64.87 & $\underline{65.20}$ \\
\hline PH50-HDI-PeD & 92.40 & $\underline{92.37}$ & 92.37 & $\underline{92.33}$ & $\underline{92.27}$ \\
\hline PH50-HDI-DEG & 0.40 & 1.13 & 0.49 & 0.49 & $\underline{0.50}$ \\
\hline PH50-IPDI & $\underline{0.27}$ & $\underline{6.48}$ & $\overline{0.93}$ & $\overline{0.94}$ & $\underline{0.97}$ \\
\hline PH50-IPDI-EG & $\underline{0.24}$ & 4.88 & $\underline{0.32}$ & $\underline{0.31}$ & $\underline{0.31}$ \\
\hline PH50-IPDI-PrD & $\underline{0.58}$ & 8.55 & $\overline{0.58}$ & $\underline{0.55}$ & $\overline{0.53}$ \\
\hline PH50-IPDI-BD & $\underline{0.31}$ & 3.11 & 0.38 & 0.40 & 0.44 \\
\hline PH50-IPDI-PeD & $\underline{0.57}$ & $\underline{13.30}$ & $\underline{0.81}$ & $\underline{0.78}$ & $\underline{0.79}$ \\
\hline PH50-IPDI-DEG & $\overline{0.33}$ & 3.35 & 0.39 & $\overline{0.40}$ & $\overline{0.40}$ \\
\hline
\end{tabular}

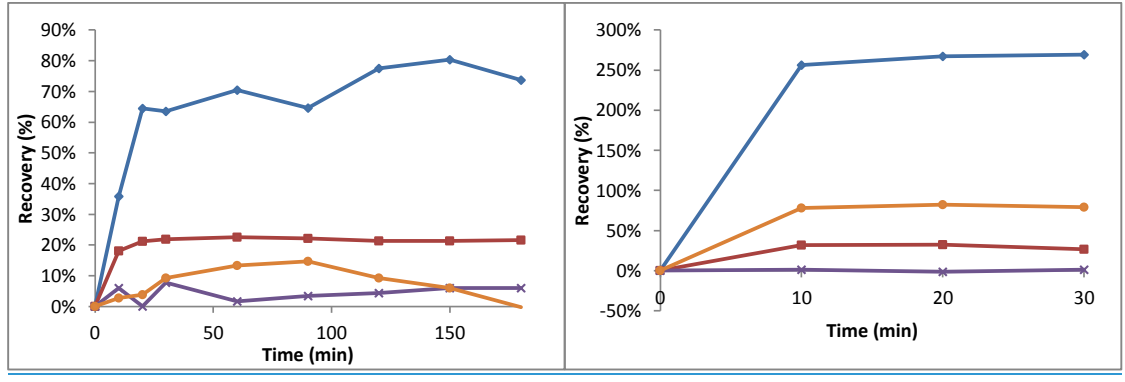

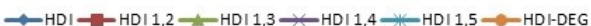

$\underline{\text { SI Figure } 6 \text { Healing of HDI based samples after } 12 \text { weeks }}$ 


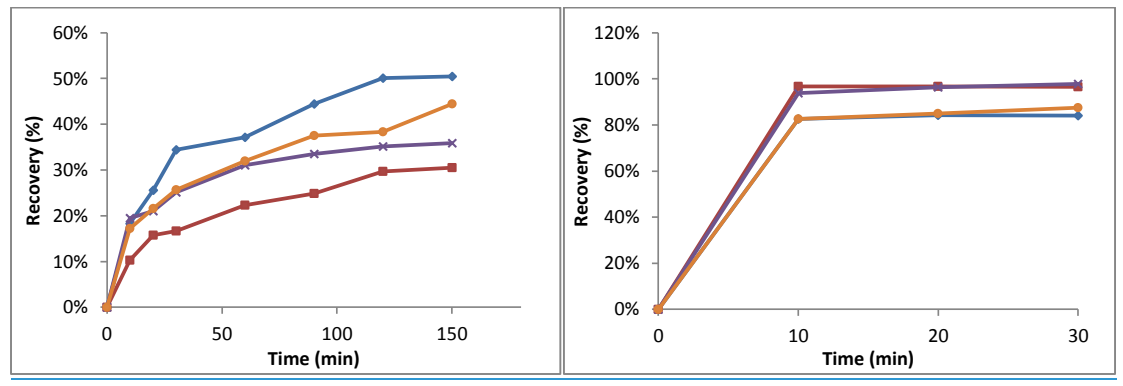

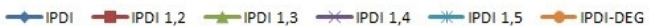

$\underline{\text { SI Figure } 7 \text { Healing of IPDI based samples after } 12 \text { weeks }}$ 

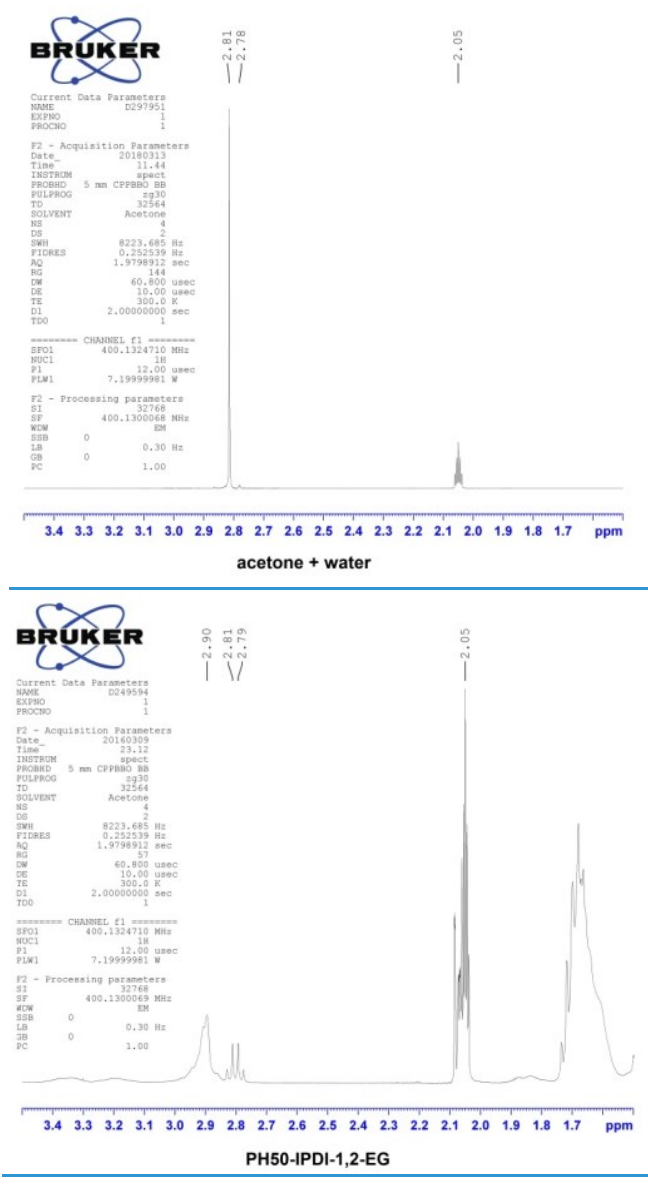

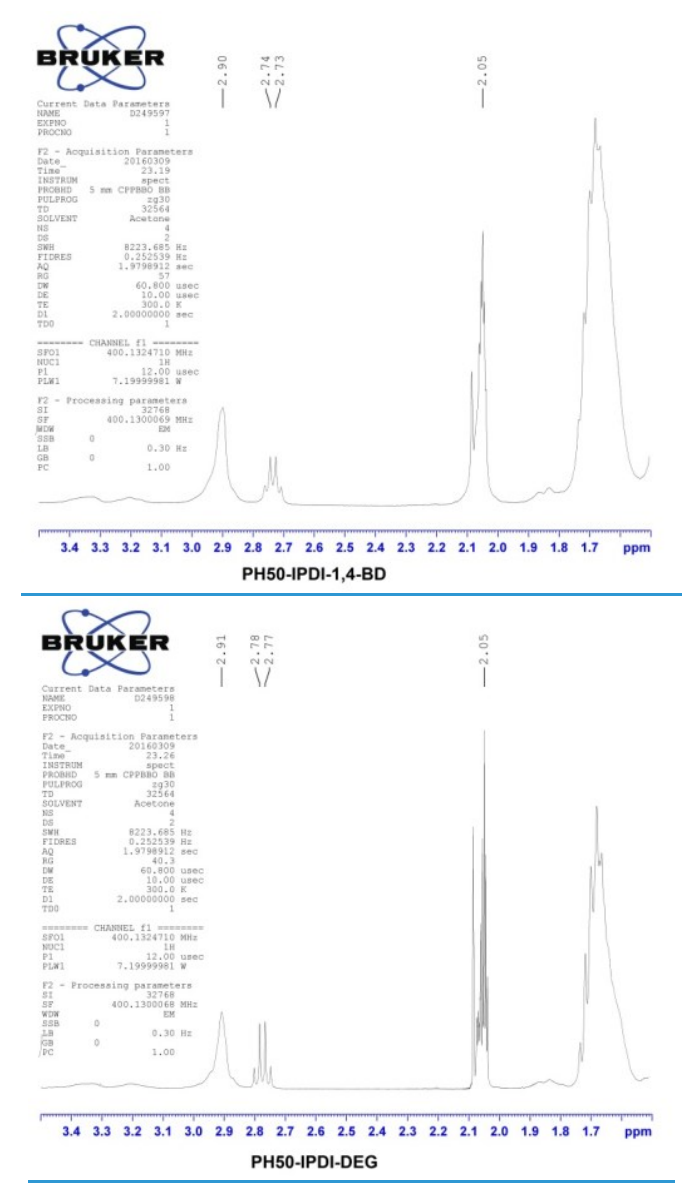

SI Figure 8 Example NMR spectra of formulations demonstrating the absence of water peaks (singlet at $\delta=2.81$ and triplet at $\delta=2.78)$ with the acetone reference peak $(\delta=2.05$, quintet). 